\title{
\begin{tabular}{l|l} 
Mitraries & DSpace@MIT
\end{tabular}
}

\author{
MIT Open Access Articles
}

\section{Markets versus Regulation: The Efficiency and Distributional Impacts of U.S. Climate Policy Proposals}

The MIT Faculty has made this article openly available. Please share how this access benefits you. Your story matters.

Citation: Rausch, Sebastian, and Valerie J. Karplus. “Markets Versus Regulation: The Efficiency and Distributional Impacts of U.S. Climate Policy Proposals." The Energy Journal 35, no. 01 (September 1, 2014).

As Published: http://dx.doi.org/10.5547/01956574.35.SI1.11

Publisher: International Association for Energy Economics (IAEE)

Persistent URL: http://hdl.handle.net/1721.1/98889

Version: Author's final manuscript: final author's manuscript post peer review, without publisher's formatting or copy editing

Terms of use: Creative Commons Attribution-Noncommercial-Share Alike 


\section{Markets versus Regulation: The Efficiency and Distributional Impacts of U.S. Climate Policy Proposals}

Sebastian Rausch and Valerie J. Karplus

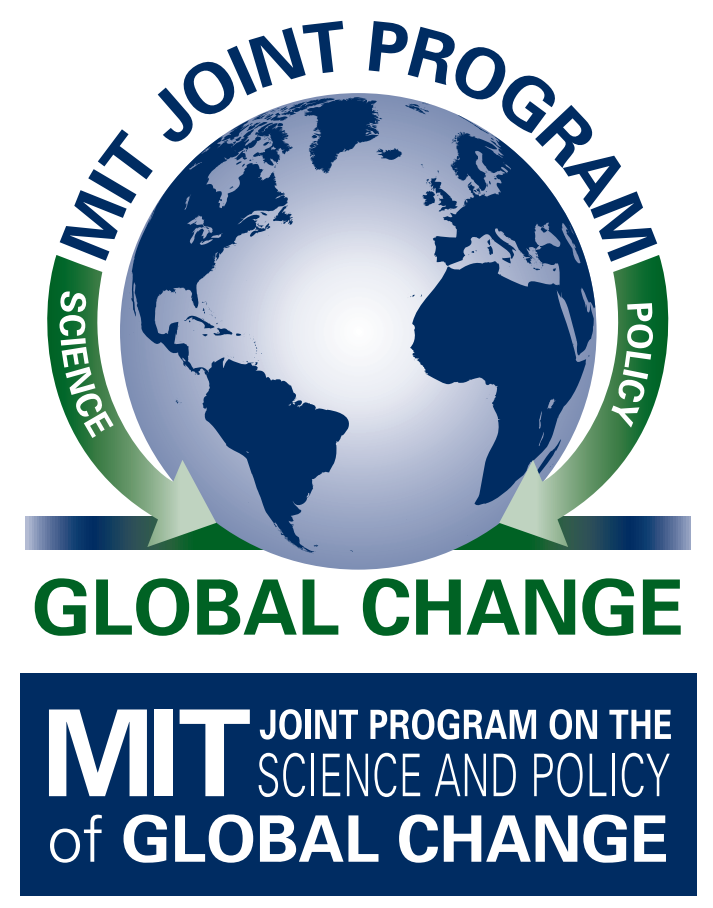

Report No. 263 May 2014 
The MIT Joint Program on the Science and Policy of Global Change combines cutting-edge scientific research with independent policy analysis to provide a solid foundation for the public and private decisions needed to mitigate and adapt to unavoidable global environmental changes. Being data-driven, the Program uses extensive Earth system and economic data and models to produce quantitative analysis and predictions of the risks of climate change and the challenges of limiting human influence on the environment-essential knowledge for the international dialogue toward a global response to climate change.

To this end, the Program brings together an interdisciplinary group from two established MIT research centers: the Center for Global Change Science (CGCS) and the Center for Energy and Environmental Policy Research (CEEPR). These two centers-along with collaborators from the Marine Biology Laboratory (MBL) at Woods Hole and short- and longterm visitors - provide the united vision needed to solve global challenges.

At the heart of much of the Program's work lies MIT's Integrated Global System Model. Through this integrated model, the Program seeks to: discover new interactions among natural and human climate system components; objectively assess uncertainty in economic and climate projections; critically and quantitatively analyze environmental management and policy proposals; understand complex connections among the many forces that will shape our future; and improve methods to model, monitor and verify greenhouse gas emissions and climatic impacts.

This reprint is one of a series intended to communicate research results and improve public understanding of global environment and energy challenges, thereby contributing to informed debate about climate change and the economic and social implications of policy alternatives.

Ronald G. Prinn and John M. Reilly,

Program Co-Directors

For more information, contact the Program office:

MIT Joint Program on the Science and Policy of Global Change

Postal Address:

Massachusetts Institute of Technology

77 Massachusetts Avenue, E19-411

Cambridge, MA 02139 (USA)

Location:

Building E19, Room 411

400 Main Street, Cambridge

\section{Access:}

Tel: (617) 253-7492

Fax: (617) 253-9845

Email: globalchange@mit.edu

Website: http://globalchange.mit.edu/ 


\title{
Markets versus Regulation: The Efficiency and Distributional Impacts of U.S. Climate Policy Proposals
}

\author{
Sebastian Rausch ${ }^{* \dagger}$ and Valerie J. Karplus
}

\begin{abstract}
Regulatory measures have proven the favored approach to climate change mitigation in the U.S., while market-based policies have gained little traction. Using a model that resolves the U.S. economy by region, income category, and sector-specific technology deployment opportunities, this paper studies the magnitude and distribution of economic impacts under regulatory versus market-based approaches. We quantify heterogeneity in the national response to regulatory policies, including a fuel economy standard and a clean or renewable electricity standard, and compare these to a cap-and-trade system targeting carbon dioxide or all greenhouse gases. We find that the regulatory policies substantially exceed the cost of a cap-and-trade system at the national level. We further show that the regulatory policies yield large cost disparities across regions and income groups, which are exaggerated by the difficulty of implementing revenue recycling provisions under regulatory policy designs.
\end{abstract}

\section{Contents}

1. INTRODUCTION 1

2. THE U.S. REGIONAL ENERGY POLICY (US REP) MODEL ........................................... 2

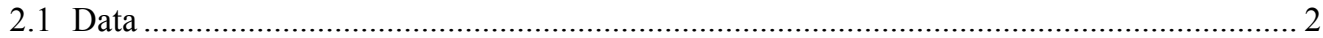

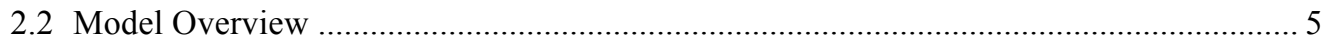

3. RESULTS

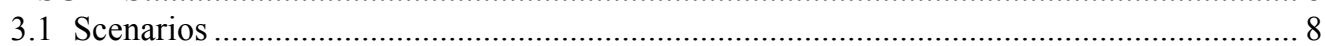

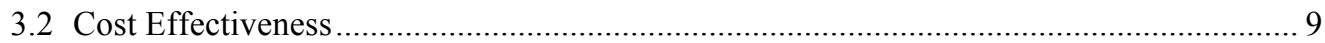

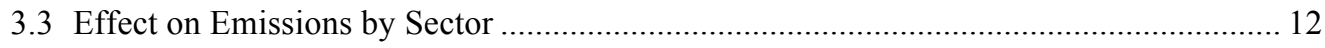

3.4 Welfare Impact by Region and Income Category .......................................................... 14

3.4.1 Regional Welfare Impact ............................................................................... 15

3.4.2 Welfare Impact by Income Category ………..................................................... 19

4. TOP-DOWN VS. BOTTOM-UP REPRESENTATION OF

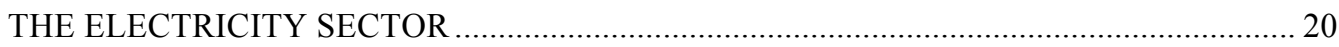

4.1 A "Top-Down" CGE Approach to Modeling Large-Scale

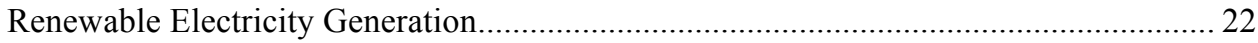

4.2 Integrating a "Bottom-up" Electricity Model in a CGE

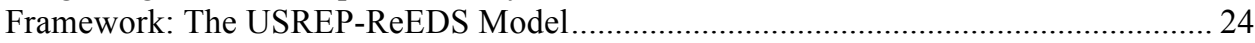

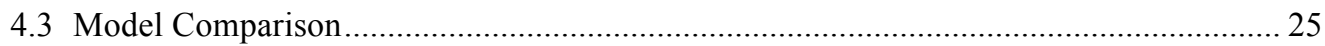

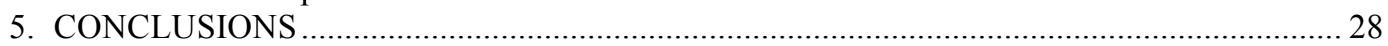

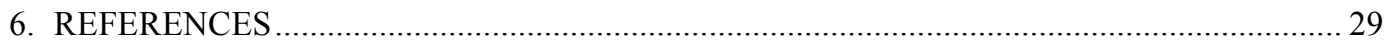

\section{INTRODUCTION}

In the absence of comprehensive legislation to curb greenhouse gas (GHG) emissions in the United States, policymakers have been pursuing climate change mitigation through sector or technology-specific regulatory measures. Comprehensive climate policies would cover most or all sources of GHG emissions and incentivize reductions at least cost through a market mechanism — such as a carbon tax, cap-and-trade system, or hybrid instrument — by achieving

${ }^{*}$ Center for Economic Research at ETH Zürich, Zürich, Switzerland.

$\dagger$ Joint Program on the Science and Policy of Global Change, Massachusetts Institute of Technology, Cambridge, MA, USA.

*Corresponding author (email: srausch@ethz.ch). 
an equalization of marginal abatement costs across participants (Metcalf, 2009). Regulatory measures, by contrast, require that GHG emissions reductions be achieved through compliance with sector-specific technology or efficiency targets. Examples of such regulatory measures include new source performance standards for power plant pollutant emissions, vehicle fuel economy standards, renewable or low carbon fuel standards, and renewable or clean electricity standards.

This paper examines the efficiency and distributional implications of federal regulation in the U.S. electric power and transportation sectors by employing a numerical simulation model with a unique treatment of regional, technology, and household income heterogeneity. The goal is to closely approximate current proposals implemented or under consideration in the U.S.

We investigate the impact on economy-wide costs and emissions reductions of introducing a clean energy standard (CES) or renewable portfolio standard (RPS), which would mandate the introduction of renewable generation (as well as other cleaner fuel sources in a CES), and a vehicle fuel economy standard modeled after the U.S. Corporate Average Fuel Economy (CAFE) Program, which mandates increases in on-road fuel economy of new vehicles sold in each vehicle model year. We explore how the costs are distributed across households in different regions and income categories. We compare the cost effectiveness and the distribution of impacts of policies alone and in combination, and investigate the welfare impact of such policies relative to an efficient instrument (in this case, a cap-and-trade system that creates a market for emissions permits). ${ }^{1}$

This paper proceeds as follows. Section 2 describes the numerical model used for quantitative policy assessments. Section 3 describes and interprets the model results. Section 4 performs a structural sensitivity analysis by investigating the impact of electricity policies in a coupled modeling framework that introduces a more detailed representation of technology. Section 5 concludes.

\section{THE U.S. REGIONAL ENERGY POLICY (US REP) MODEL}

\subsection{Data}

This study makes use of a comprehensive energy-economic data set that features a consistent representation of energy markets in physical units as well as detailed economic accounts of

${ }^{1}$ It is important to note that this paper does not aim at identifying any optimal mix of policy instruments, nor does it claim that an economy-wide cap-and-trade regulation is always the most cost-effective policy instrument. Costeffectiveness depends importantly on how policies interact with distortions in the economy created by the broader fiscal system (see, for example, Harberger, 1964; Bovenberg and Goulder, 1996; Goulder et al., 1999). The costs of market-based policies that do not offset the tax-interaction effect with the revenue-recycling benefit can be dramatically higher, particularly for the scale of $\mathrm{CO}_{2}$ reductions considered here (Parry and Williams III, 2011). Regulatory approaches targeted to individual sectors would thus be less attractive relative to a comprehensive cap-and-trade policy if the latter would exploit revenue recycling options. As we assume throughout the paper that the revenue from a federal cap-and-trade regulation is recycled lump-sum, the estimates concerning the relative cost-effectiveness of regulatory policies provided in this paper should be best viewed as providing a lower bound. 
regional production, bilateral trade, and energy resources for the year 2006. The data set merges detailed state-level data for the U.S. with national economic and energy data. Social accounting matrices (SAM) in our hybrid data set are based on data from the IMPLAN (IMpact analysis for PLANning) data (IMPLAN, 2008) and U.S. state-level accounts of energy balances and prices from the Energy Information Administration (EIA, 2009). Table 1 provides an overview of the data sources used.

The IMPLAN data provide consistent regional accounts of production, consumption, and bilateral trade for the 50 U.S. states (and the District of Columbia). The data set includes inputoutput tables for each state that identify 509 commodities and existing taxes. Bilateral state-tostate trade data in the IMPLAN database are derived using a gravity approach (Lindall et al., 2006). ${ }^{2}$ The base year for the IMPLAN accounts in the version we use here is 2006 . To improve the characterization of energy markets in the IMPLAN data, we use constrained least-squares optimization techniques to merge IMPLAN data with data on physical energy quantities and energy prices from the Energy Information Administration's State Energy Data System for 2006 (EIA, 2009). ${ }^{3}$

Table 1. Data sources for the energy-economic data set.

\begin{tabular}{|c|c|}
\hline Data and parameters & Source \\
\hline Social accounting matrices & IMPLAN (2008) \\
\hline bi-lateral trade & Gravity-based analysis (Lindall et al., 2006) \\
\hline pooled energy trade & State Energy Data System (EIA, 2009) \\
\hline Physical energy flows \& energy prices & State Energy Data System (EIA, 2009) \\
\hline Fossil fuel reserves & U.S. Geological Survey (USGS, 2009) \\
\hline and biomass supply & $\begin{array}{l}\text { U.S. Department of Energy (DOE, 2009), Dyni (2006) } \\
\text { and Oakridge National Laboratories (2009) }\end{array}$ \\
\hline High-resolution wind data & $\begin{array}{l}\text { Wind Integration Data sets, National Renewable } \\
\text { Energy Laboratory (NREL, 2010) }\end{array}$ \\
\hline Non- $\mathrm{CO}_{2}$ GHG inventories & U.S. Environmental Protection Agency (EPA, 2009) \\
\hline and endogenous costing & Hyman et al. (2002) \\
\hline Marginal personal income tax rates & NBER's TAXSIM model (Feenberg and Coutts, 1993) \\
\hline Trade elasticities & $\begin{array}{l}\text { Global Trade Analysis Project (2008) and own } \\
\text { calibration }\end{array}$ \\
\hline Energy demand and supply elasticities & Paltsev et al. (2005) \\
\hline Passenger vehicle transportation & U.S. Department of Transportation (2009) \\
\hline
\end{tabular}

${ }^{2}$ The IMPLAN Trade Flows Model draws on three data sources: the Oak Ridge National Labs county-to-county distances by mode of transportation database, the Commodity Flows Survey (CFS) ton-miles data by commodity, and IMPLAN commodity supply and demand estimates by county.

${ }^{3}$ Aggregation and reconciliation of IMPLAN state-level economic accounts to generate a micro-consistent benchmark data set which can be used for model calibration is accomplished using ancillary tools documented in Rausch and Rutherford (2009). 
Table 2. USREP model details.

\begin{tabular}{|c|c|c|c|c|c|c|c|c|c|}
\hline Regions & \multicolumn{4}{|c|}{$\begin{array}{l}\text { - Pacific (PACIF) } \\
\text { - California (CA) } \\
\text { - Alaska (AK) } \\
\text { - Mountain (MOUNT) } \\
\text { - North Central (NCENT) } \\
\text { - Texas (TX) }\end{array}$} & \multicolumn{5}{|c|}{$\begin{array}{l}\text { - South Central (SCENT) } \\
\text { - North East (NEAST) } \\
\text { - South East (SEAST) } \\
\text { - Florida (FL) } \\
\text { - New York (NY) } \\
\text { - New England (NENGL) }\end{array}$} \\
\hline \multirow{5}{*}{ Sectors } & \multicolumn{4}{|c|}{ Non-Energy sectors } & \multicolumn{5}{|c|}{$\begin{array}{l}\text { - Agriculture (AGR) } \\
\text { - Services (SRV) } \\
\text { - Energy-intensive products (EIS) } \\
\text { - Other industries products (OTH) } \\
\text { - Commercial Transportation (TRN) } \\
\text { - Household vehicle transportation (HVT) }\end{array}$} \\
\hline & \multicolumn{4}{|c|}{ Final demand sectors } & \multicolumn{5}{|c|}{$\begin{array}{l}\text { - Household transportation } \\
\text { - Other household demand } \\
\text { - Government demand } \\
\text { - Investment demand }\end{array}$} \\
\hline & \multirow{3}{*}{\multicolumn{4}{|c|}{$\begin{array}{l}\text { Energy supply and } \\
\text { conversion }\end{array}$}} & \multicolumn{5}{|c|}{$\begin{array}{ll} & \cdot \text { Coal (COL) } \\
\text { Fuels } & \cdot \text { Natural gas (GAS) } \\
& \cdot \text { Crude oil (CRU) } \\
& \cdot \text { Refined oil (OIL) }\end{array}$} \\
\hline & & & & & \multicolumn{2}{|c|}{ Electricity (ELE) } & $\begin{array}{l}\text { - Conver } \\
\text { - Existin } \\
\text { - Hydro } \\
\end{array}$ & $\begin{array}{l}\text { ntional fos } \\
\text { ig nuclear }\end{array}$ & \\
\hline & & & & & \multicolumn{2}{|c|}{$\begin{array}{l}\text { Advanced energy } \\
\text { supply technologies }\end{array}$} & \multicolumn{2}{|c|}{ (see Table 3) } & \\
\hline $\begin{array}{r}\text { Primary } \\
\text { production } \\
\text { factors }\end{array}$ & \multicolumn{2}{|c|}{$\begin{array}{l}\text { - Capital } \\
\text { - Labor } \\
\text { - Land }\end{array}$} & \multicolumn{2}{|c|}{$\begin{array}{l}\text { - Wind resources } \\
\text { - Hydro } \\
\text { resources }\end{array}$} & \multicolumn{2}{|c|}{$\begin{array}{l}\text { - Coal resources } \\
\text { - Nuclear } \\
\text { resources }\end{array}$} & \multicolumn{3}{|c|}{$\begin{array}{l}\text { - Crude oil resources } \\
\text { - Natural gas } \\
\text { resources }\end{array}$} \\
\hline $\begin{array}{r}\text { Household } \\
\text { income classes } \\
(\$ 1,000 \text { annually })\end{array}$ & $<10$ & $10-15$ & $15-25$ & $25-30$ & $30-50$ & $50-75$ & $75-100$ & $100-150$ & $>150$ \\
\hline
\end{tabular}

For this study, we aggregate the data set to 12 U.S. regions, 10 commodity groups, and 9 households grouped by annual income classes (see Table 2). States identified in the model include California, Texas, Florida, and New York, along with several other multi-state regional composites. Mapping of states to aggregated regions is shown in Figure 1. This structure separately identifies larger states, allows representation of separate electricity interconnects, and captures some of the diversity among states in use and production of energy. Our commodity aggregation identifies five energy sectors and five non-energy composites. Energy commodities include coal (COL), natural gas (GAS), crude oil (CRU), refined oil (OIL), and electricity (ELE), which distinguishes energy goods and specifies substitutability between fuels in energy demand. Elsewhere, we distinguish energy-intensive products (EIS), other manufacturing (OTH), agriculture (AGR), commercial transportation (TRN), household vehicle transportation (HVT), and services (SRV). Primary factors in the data set include labor, capital, and land, as well as fossil fuels and natural resources. We forecast both $\mathrm{CO}_{2}$ and non- $\mathrm{CO}_{2}$ greenhouse gases. Non$\mathrm{CO}_{2}$ greenhouse gases are based on U.S. EPA inventory data (EPA, 2009), and are included following the approach in Paltsev et al. (2005) with endogenous costing of abatement measures 
(Hyman et al., 2002). Energy supply is regionalized by incorporating data for regional crude oil and natural gas reserves (DOE, 2009), coal reserves estimated by the U.S. Geological Survey (USGS, 2009), and shale oil (Dyni, 2006). Our approach to characterize wind resource and incorporate electricity generation from wind in the model is described in detail in Section 4.1. We derive regional supply curves for biomass from data from Oakridge National Laboratories (2009) that describes quantity and price pairs for biomass supply for each state.

Our data set permits calculation of existing tax rates comprised of sector and region-specific ad valorem output taxes, payroll taxes and capital income taxes. The IMPLAN data has been augmented by incorporating regional tax data from the NBER TAXSIM model (Feenberg and Coutts, 1993) to represent marginal personal income tax rates by region and income class.

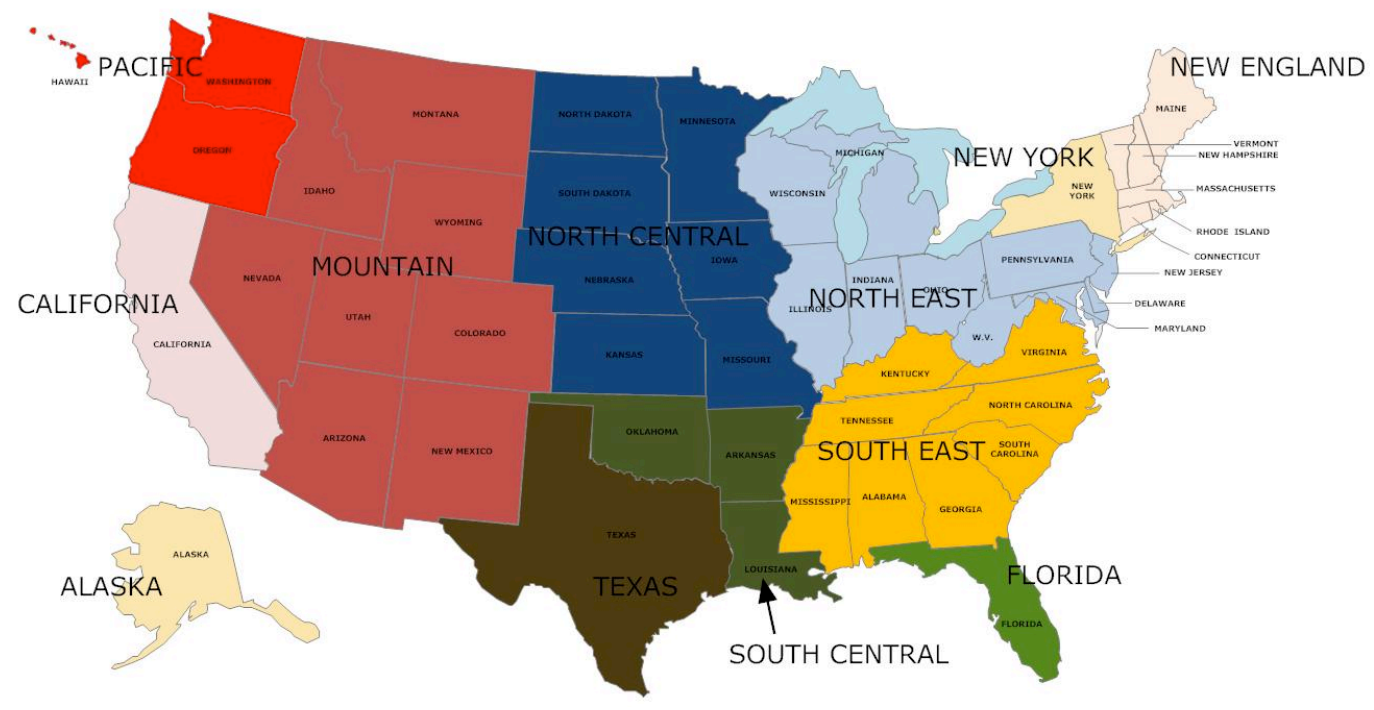

Figure 1. Regions in the USREP model.

\subsection{Model Overview}

Our modeling framework draws on a multi-commodity, multi-region, multi-household numerical general equilibrium model of the U.S. economy. The key features of the model are briefly outlined below and described in detail in Rausch et al. (2010a, 2010b). ${ }^{4}$ The model assumes a recursive-dynamic approach implying that economic agents have myopic expectations and base their decisions on current period information.

In each industry gross output is produced using inputs of labor, capital, and natural resources including coal, natural gas, crude oil, and land, and produced intermediate inputs. We employ constant-elasticity-of-substitution (CES) functions to characterize how production technologies respond to changes in energy and other input prices; the IMPLAN data describe the initial production systems. All industries are characterized by constant returns to scale (except for fossil

\footnotetext{
${ }^{4}$ These papers also provide detail on the elasticities of substitution used to parameterize the model which we do not provide below.
} 
fuels and agriculture, which are produced subject to decreasing returns to scale) and are traded in perfectly competitive markets.

Advanced energy supply options are specified as "backstop" technologies that enter endogenously if and when they become economically competitive with existing technologies. Competitiveness of advanced technologies depends on their initial cost disadvantage compared to conventional technologies, in addition to the endogenously determined input prices. The advanced technology options are summarized in Table 3.

Table 3. Advanced energy supply technologies.

\begin{tabular}{|c|c|c|}
\hline & Technology & Description \\
\hline \multirow{3}{*}{$\begin{array}{l}\text { Perfect } \\
\text { Conventional } \\
\text { Fossil Fuel } \\
\text { Substitutes }\end{array}$} & Coal gasification & Converts coal into a perfect substitute for natural gas. \\
\hline & Biomass liquids & Converts biomass into a perfect substitute for refined oil. \\
\hline & Biomass electricity & Converts biomass into a perfect substitute for electricity \\
\hline \multirow{7}{*}{$\begin{array}{l}\text { Imperfect } \\
\text { Conventional } \\
\text { Fossil Fuel } \\
\text { Substitutes }\end{array}$} & Wind / no backup & $\begin{array}{l}\text { Converts intermittent wind resources into an imperfect } \\
\text { substitute for electricity. }\end{array}$ \\
\hline & Wind / gas backup & $\begin{array}{l}\text { Creates a perfect substitute for electricity by jointly } \\
\text { building wind turbines and natural gas generation. }\end{array}$ \\
\hline & Wind / biomass backup & $\begin{array}{l}\text { Creates a perfect substitute for electricity by jointly } \\
\text { building wind and biomass generation. }\end{array}$ \\
\hline & Advanced gas & $\begin{array}{l}\text { Based on natural gas combined cycle (NGCC) } \\
\text { technology that converts natural gas into electricity. }\end{array}$ \\
\hline & Advanced gas / CCS & $\begin{array}{l}\text { Natural gas combined cycle technology that captures } 90 \% \\
\text { or more of the } \mathrm{CO}_{2} \text { produced in generating electricity. }\end{array}$ \\
\hline & Advanced coal / CCS & $\begin{array}{l}\text { Integrated coal gasification combined cycle (IGCC) that } \\
\text { captures } 90 \% \text { or more of the } \mathrm{CO}_{2} \text { produced in } \\
\text { generating electricity. }\end{array}$ \\
\hline & Advanced nuclear & $\begin{array}{l}\text { Next generation of nuclear power plants incorporating } \\
\text { estimated costs of building new nuclear power plants in } \\
\text { the future. }\end{array}$ \\
\hline
\end{tabular}

Three technologies produce perfect substitutes for conventional fossil fuels (natural gas from coal, a crude oil product from shale oil, and refined oil from biomass). The remaining nine are electricity generation technologies (biomass, wind without backup, wind with gas backup, wind with biomass backup, natural gas combined cycle with and without carbon capture and sequestration, integrated coal gasification combined cycle with and without carbon capture and sequestration, and advanced nuclear). We adopt a top-down approach of representing technologies following Paltsev et al. (2005, p. 31-42) where each technology can be described through a nested CES function. The logic behind our approach to representing electricity generated from intermittent wind resources is explained in detail in Section 4.1.

Consumption, labor supply, and savings result from the decisions of representative households in each region maximizing utility subject to a budget constraint that requires that full consumption equals income in a given period. Lacking specific data on capital ownership, households are assumed to own a pool of U.S. capital - that is, they do not disproportionately 
own capital assets within the region in which they reside. ${ }^{5}$ Given input prices gross of taxes, firms maximize profits subject to technology constraints.

Firms operate in perfectly competitive markets and maximize their profit by selling their products at a price equal to marginal costs. In each region, a single government entity approximates government activities at all levels - federal, state, and local.

We adopt a putty-clay approach where a fraction of previously installed capital becomes nonmalleable and frozen into the prevailing techniques of production. Vintaged production in a given industry that uses non-malleable capital is subject to a fixed-coefficient transformation process in which the quantity shares of capital, labor, intermediate inputs and energy by fuel type are set to be identical to those that prevailed in the period when the capital was installed. Each of the sector-specific vintages is tracked through time as a separate capital stock. This formulation means that the model exhibits a short-run and long-run response to changes in relative prices. The substitution response in a single period to a change in prices in that period is a combination of the long-run substitution possibilities, weighted by output produced by malleable capital, and no substitution, weighted by output produced with vintaged capital.

With the exception of crude oil, which is modeled as a homogeneous good, intermediate and final consumption goods are differentiated following the Armington (1969) assumption. For each demand class, the total supply of a particular good is a CES composite of a domestically produced variety (i.e., locally produced and imported from domestic markets) and an imported (from foreign markets) one. As described in Rausch et al. (2010a), USREP models the U.S. as a large open economy with price-responsive imports and exports to and from international markets.

All goods are tradable. Depending on the type of commodity, we distinguish three different representations of intranational trade. First, bilateral flows for all non-energy goods are represented as Armington goods, which like goods from other regions are imperfectly substitutable for domestically produced goods. Second, domestically traded energy goods, except for electricity, are assumed to be homogeneous products, i.e. there is a national pool that demands domestic exports and supplies domestic imports. This assumption reflects the high degree of integration of intra-U.S. markets for natural gas, crude and refined oil, and coal. Third, we differentiate six regional electricity pools that are designed to provide an approximation of the existing structure of independent system operators (ISO) and the three major interconnections in the U.S. More specifically, we distinguish the Western, Texas ERCOT and Eastern

\footnotetext{
${ }^{5}$ The ownership of natural resources and wind is, however, assumed to be regional. Lacking empirical data on ownership patterns from these resources, the alternative and extreme case would be to assume that income from natural resources is also distributed in proportion to capital. On one hand, the assumption of pooled ownership of capital tends to average out distributional impacts across the nation, while on the other hand, the assumption of regional ownership of natural resources may overestimate the size of regional impacts.
} 
interconnections, and in addition identify AK, NENGL, and NY as separate regional pools. ${ }^{6}$ Within each regional pool, we assume that traded electricity is a homogenous good, and that no electricity is traded among regional pools.

Our framework incorporates a detailed representation of passenger vehicle transport that permits projections of vehicle-miles traveled (VMT), fleet stock turnover, and fuel price-induced investment in fuel efficiency. This permits studies of policies that target improvements in vehicle fuel efficiency, differentiate between newly purchased and pre-existing vehicle stocks in each period, and result in changes in overall vehicle-miles traveled as well as the fuel use and GHG emissions of new and pre-existing vehicles. These features are similar to those introduced into the MIT EPPA model (Paltsev et al., 2005) and are described in detail in Karplus et al. (2013b).

Numerically, the equilibrium is formulated as a mixed complementarity problem (MCP) (Mathiesen, 1985; Rutherford, 1995). Our complementarity-based solution approach comprises two classes of equilibrium conditions: zero profit and market clearance conditions. The former condition determines a vector of activity levels and the latter determines a vector of prices. We formulate the problem in GAMS and use the mathematical programming system MPSGE (Rutherford, 1999) and the PATH solver (Dirkse and Ferris, 1995) to solve for non-negative prices and quantities.

\section{RESULTS}

\subsection{Scenarios}

Our core scenarios follow the policy scenarios defined in the EMF 24 U.S. study (see the overview paper of this study; Fawcett et al., 2012). In addition to a business-as-usual scenario ("BAU", called "US01F"), ${ }^{7}$ we consider the following six policy scenarios:

(1) A national cap-and-trade policy that allows for cumulative GHG emissions from 2012 through 2050 associated with a linear reduction from 2012 levels to 50\% below 2005 levels in 2050 (“CAT50\%”, "US03F”)

(2) A federal renewable portfolio standard for electricity which mandates that $20 \%$ by 2020 , $30 \%$ by $2030,40 \%$ by 2040 , and $50 \%$ by 2050 of electricity has to be produced from renewable energy (including hydropower), and that all new coal power plants capture and store more than $90 \%$ of their $\mathrm{CO}_{2}$ emissions ("Electricity (Coal+RPS)", "US11F")

(3) A federal clean energy standard for electricity under which all renewable energy sources and nuclear receive full credit while fossil electricity with carbon capture and storage (CCS) technologies are credited at $90 \%$ and natural gas at $50 \%$ with targets defined as

${ }^{6}$ The regional electricity pools are thus defined as follows: NENGL, NY, TX and AK each represent a separate pool. The Western Interconnection comprises CA, MOUNT and PACIF. The Eastern Interconnection comprises NEAST, SEAST and FL.

${ }^{7}$ The first label specifies the scenario name used in this paper; the second label refers to the scenario name used in the overview piece of the EMF24 study. 
linearly increasing from reference levels in 2012 to $50 \%$ by $2020,60 \%$ by $2025,70 \%$ by $2030,80 \%$ by $2035,90 \%$ by 2040 and thereafter ("Electricity (Coal+CES)", "US27F")

(4) A federal transport policy establishing a fuel economy standard for new light-duty vehicles that specifies a linear increase in the fuel economy of new vehicles, starting in 2012, to 3 times 2005 levels sectors ("Electricity (Coal+RPS) and Transport", "US05F");

(5) A scenario that combines both regulatory policies for the electricity and transportation sectors ("Electricity (Coal+RPS) and Transport", "US05F"), transportation

(6) A scenario that layers a federal cap-and-trade policy on top of the two sectoral policies ("Electricity (Coal+RPS) and Transport and CAT50\%", "US07F")

Throughout all scenarios - including the regulatory policy scenarios - real government spending is held fixed at the baseline ("BAU") level through endogenous lump-sum transfers or taxes. These are assumed to be uniform across households in different regions and income classes.

\subsection{Cost Effectiveness}

The cost effectiveness of policy is inherently linked to abatement flexibility. Important sources of flexibility include the ability to allocate abatement across gases, sectors, technologies, and time. To the extent that target gas, sector, technology, and timetable are constrained, regulatory policies will impose equal or greater costs relative to an economy-wide market-based instrument with full flexibility (in a first-best setting). Adding regulatory policies in the presence of an economy-wide instrument also reduces abatement flexibility, as specified sectors or technologies deliver a portion of the overall reduction that would otherwise represent least cost solutions. These observations are consistent with the theoretical and empirical literature (Paltsev et al., 2009; Böhringer and Rosendahl, 2010; Fischer and Preonas, 2010; Pethig and Wittlich, 2009; del Rio Gonzalez, 2007). In contrast to both cap-and-trade instruments, all of the regulatory policies implemented, and as modeled here, are constrained to act on a target sector and fixed abatement schedule, significantly reducing abatement flexibility. ${ }^{8}$

Our analysis illustrates the welfare penalties associated with reductions in abatement flexibility. Figure 2 shows for each policy the percentage change in cumulative GHG (or $\mathrm{CO}_{2}$ emissions from 2012-2050 against the net present value of welfare change over the same period, expressed in trillion $2005 \$$. Welfare costs are measured as equivalent variation relative to the baseline (no policy) scenario. The two solid lines show the "efficient" abatement frontier, i.e. the

${ }^{8}$ In the presence of distorted factor markets, however, it is not clear a priori that a cap-and-trade policy is superior in terms of welfare compared to a regulatory policy. Cap-and-trade policies may lead to a large increase in the price of consumption relative to a regulatory policy, thus implying a lower real wage and a larger reduction in labor supply. If there are pre-existing taxes on labor, the reduction in labor supply has a first-order efficiency cost, which has been termed the tax-interaction effect (Parry et al., 1998), and can be larger under a cap-and-trade relative to a regulatory policy. Similar effects might arise if intra- and intertemporal distortions associated with capital markets are corrected. However, regulatory policies fail to exploit the revenue-recycling effect, as they do not generate revenue that can be used to cut distortionary marginal tax rates. Initial exploratory analysis with the USREP model did find evidence for a strong tax-interaction effect that would make regulatory policies more cost effective. 
locus of points that corresponds to the impact of a market mechanism (here modeled as a system of tradable permits). The frontiers are shown both for policies that constrain all $\mathrm{GHGs}$ or $\mathrm{CO}_{2}$ only. Reducing coverage from all GHGs to $\mathrm{CO}_{2}$ alone adds to the cost of policy, corresponding to a shift of the frontier to the right. Both of these policies retain broad sectoral coverage and intertemporal flexibility through provisions for banking and borrowing. ${ }^{9}$

The two frontiers corresponding to $\mathrm{GHG}$ and $\mathrm{CO}_{2}$ cap-and trade instruments in Figure 2 provide a benchmark against which the various regulatory policies can be compared. We first consider combinations of cap-and-trade policies with regulatory instruments. At the national level we find that the welfare reduction generated by the CAT50\% ranks among the smallest of all the policies, while it produces the largest total cumulative reduction. Adding the vehicle fuel economy and electricity regulations to the $\mathrm{CO}_{2}$ or GHG cap-and-trade policy increases the total discounted welfare cost by $60 \%$ or $90 \%$, respectively.

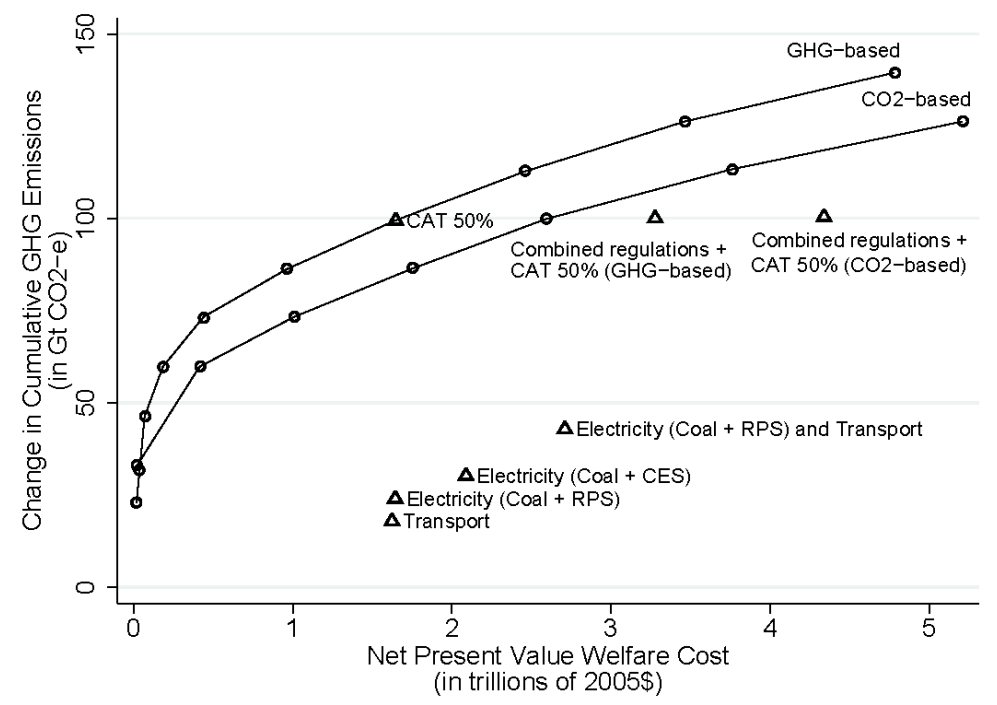

Figure 2. Net present value (NPV) of welfare cost and cumulative GHG emissions reductions of regulatory and market-based climate policies. NPV is calculated using an annual discount rate of $4 \%$. "GHG-based" refers to CAT policies designed to achieve emissions reduction from multiple greenhouse gases based on their $\mathrm{CO}_{2}$ equivalents. " $\mathrm{CO}_{2}$-based" refers to CAT policies that only target $\mathrm{CO}_{2}$.

All of the regulatory policies produce points located inside (and far from) the efficient frontier. Figure 2 shows the magnitude of the welfare penalty associated with each of the regulatory instruments in terms of how they compare to both the efficient frontiers as well as to each other. In all cases, the emissions reductions achieved are much lower, given that policies target modest reductions from specific sectors. These reductions, however, are achieved with far less costeffective solutions - for the same cost, a fuel economy standard ("transport") or a renewable-

\footnotetext{
${ }^{9}$ It should be noted that there may be cap-and-trade policies that are more cost effective due to exploiting the
} revenue-recycling effect. 
energy based electricity standard ("Coal+RPS") would achieve only one-fourth of the reductions attained under a cap-and-trade system. Put differently, an equivalent level of emissions reduction could be achieved under a cap-and-trade system for less than $5 \%$ of the cost of either regulatory policy. The large discrepancy can be traced back to abatement flexibility-regulatory policies imposed on the electricity or transportation sectors would encourage the application of only a subset of the abatement options that a cap-and-trade policy would employ. Indeed, the cost of combining the two regulatory policies exceeds that of a cap-and-trade system $(1.1 \%$ compared to $0.9 \%$ ), while the emissions reductions are barely half of the level achieved under a cap-and-trade system.

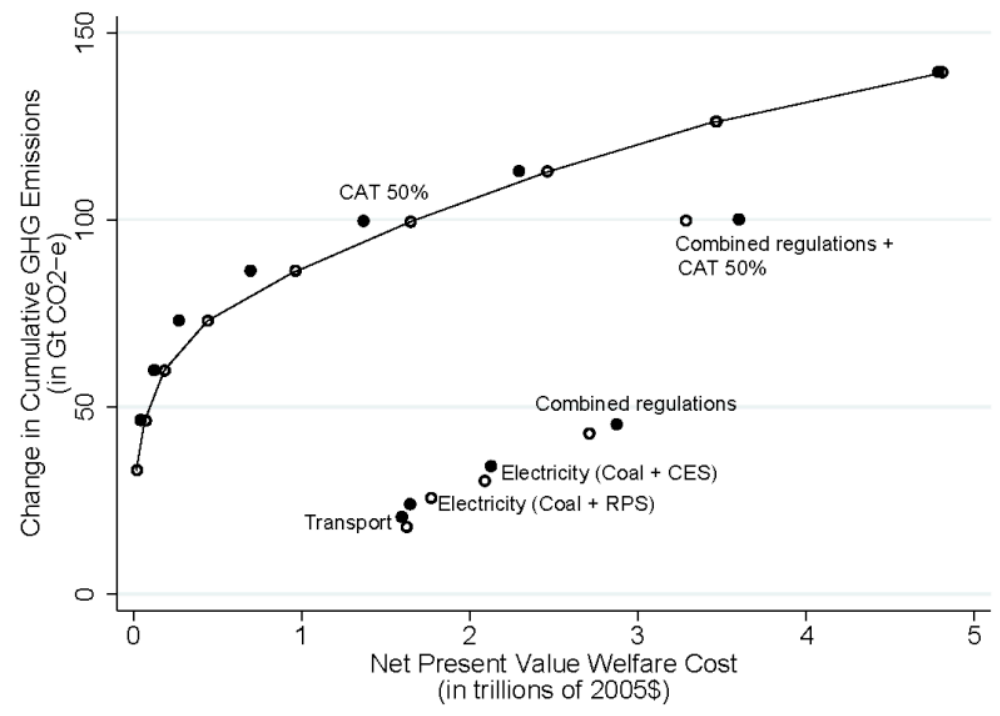

Figure 3. Net present value (NPV) of welfare cost and cumulative GHG emissions reductions of regulatory and market-based climate policies for different technology sensitivities. NPV calculated using an annual discount rate of $4 \%$. Hollow circles refer to "Low CCS/Nuclear and High Renewable Energy" technology assumptions. Solid circles refer to "High CCS/Nuclear and Low Renewable Energy" technology assumptions.

These results are not markedly affected by alternative assumptions for technology cost, as shown in Figure 3. We examine a case with low CCS/nuclear and high renewable energy costs and one with the reverse, high CCS/nuclear and low renewable energy costs. On the frontier, sensitivity of the total cost to changes in relative costs of these electricity sector abatement options initially increases with the magnitude of emissions reductions required, before decreasing again at reduction levels upwards of around $125 \mathrm{Gt} \mathrm{CO}_{2}$-e, suggesting that at higher levels of reduction the relative costs no longer affect technology deployment decisions at the margin. The direction of the effect in the electricity scenarios depends on the role of renewable energy and carbon capture and storage (CCS) as the preferred solution under the policy constraint: high cost renewable energy increases the cost of compliance in the "Coal+RPS" scenario, but has less of an effect in the "Coal+CES" policy given that other low carbon alternatives, particularly natural gas, can be used to comply with the policy. The GHG emissions reduction trajectories under each policy over time are shown in Figure 4. 


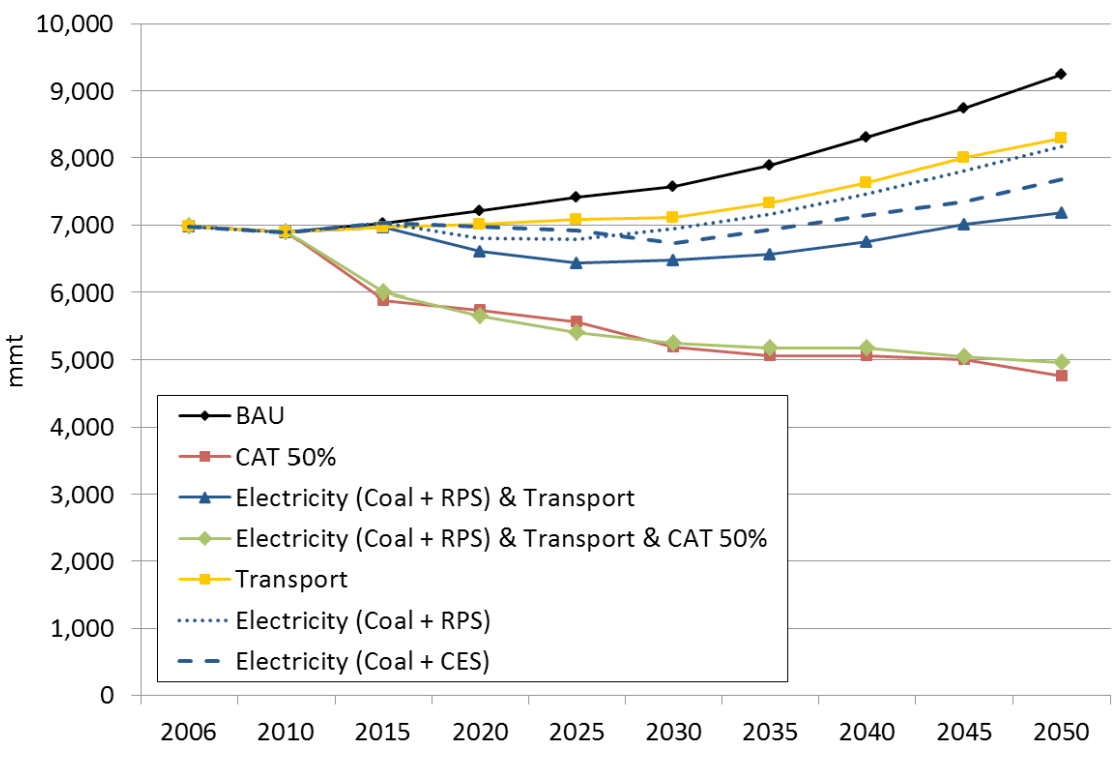

Figure 4. U.S. GHG emissions over time.

\subsection{Effect on Emissions by Sector}

We now turn to consider the distribution of impacts by sector, shown in Table 4. The capand-trade policy elicits broad sectoral participation (we focus here only on the GHG policy), with the reduction burden spread across the electricity, agriculture, energy-intensive industries, manufacturing, and commercial transport sectors. Private transport, by contrast, proves to be a relatively costly abatement option, consistent with other studies, and does not participate significantly in the least-cost response (Karplus et al., 2013a; Davidson and van Essen, 2009; Schafer and Jacoby, 2006). Under a policy that targets private and commercial transport, reductions in these sectors (19\% and $18 \%$, respectively) substantially exceed those resulting under a cap-and-trade system, with additional modest reductions in other sectors resulting from the indirect effects on income and prices imposed by the policy. Combining electricity and transport regulatory policies results in nearly additive total reductions (14\%), given that these activities are largely separate and co-benefits are limited.

Comparing the cap-and-trade policy combined with regulatory policies to the cap-and-trade policy imposed alone, we find that the regulatory policies significantly increase the contribution of the electricity and transport sectors to overall abatement at the expense of more cost effective abatement opportunities in agriculture, energy-intensive industries, and manufacturing. For example, the contribution of the energy-intensive industries to overall abatement drops from $23 \%$ to $14 \%$ when both regulatory policies are added to a cap-and-trade system, and similar decreases are observed for agriculture, manufacturing, and services. This response is also due to the lower allowance prices under the approaches that involve the regulatory policies as these policies shift the burden on the regulated industries and off the non-regulated sectors of the economy. 
Table 4. Percentage change in cumulative (2012-2050) U.S. GHG emissions by sector and sectoral contribution to overall abatement.

\begin{tabular}{|c|c|c|c|c|c|c|}
\hline & CAT $50 \%$ & Transport & $\begin{array}{l}\text { Electricity } \\
\text { (Coal+RPS) }\end{array}$ & $\begin{array}{l}\text { Electricity } \\
\text { (Coal+CES) }\end{array}$ & $\begin{array}{l}\text { Electricity } \\
\text { (Coal+RPS) } \\
\text { +Transport }\end{array}$ & $\begin{array}{l}\text { Electricity } \\
\text { (Coal+RPS) } \\
\text { +Transport } \\
\text { +CAT } 50 \% \\
\end{array}$ \\
\hline All Sectors & -22 & -7 & -6 & -7 & -14 & -25 \\
\hline $\begin{array}{l}\text { Commercial } \\
\text { transport }\end{array}$ & $-8(9)$ & $-19(68)$ & $-0(1)$ & $0.0(-0)$ & $-20(37)$ & $-21(21)$ \\
\hline $\begin{array}{l}\text { Private } \\
\text { transport }\end{array}$ & $-3(2)$ & $-18(37)$ & $0(-0)$ & $0(-1)$ & $-18(20)$ & $-19(12)$ \\
\hline Electricity & $-33(44)$ & $1(-5)$ & $-20(95)$ & $-25(99)$ & $-18(40)$ & $-28(34)$ \\
\hline Agriculture & $-45(16)$ & $2(-2)$ & $-1(2)$ & $-1(1)$ & $1(-0)$ & $-41(13)$ \\
\hline $\begin{array}{l}\text { Energy-intensive } \\
\text { industries }\end{array}$ & $-23(10)$ & $2(-3)$ & $-0(0)$ & $1(-1)$ & $2(-1)$ & $-14(5)$ \\
\hline Refined oil & $-24(5)$ & $-17(10)$ & $0(0)$ & $-0(0)$ & $-17(5)$ & $-27(5)$ \\
\hline Manufacturing & $-44(12)$ & $5(-4)$ & $-1(1)$ & $-1(1)$ & $4(-2)$ & $-35(9)$ \\
\hline Services & $-25(3)$ & $1(-0)$ & $-3(1)$ & $-1(0)$ & $-2(0)$ & $-20(2)$ \\
\hline
\end{tabular}

Note: Figures before parentheses refer to percentage change in emissions by sector relative to "business-as-usual".

Figures in parentheses refer to sectoral emissions reductions as a percentage of total abatement relative to

"business-as-usual".

Since the electricity sector plays a major role in abatement in most of the policy scenarios considered, we investigate the impact on the composition of the electricity generation mix. Figure 5 shows the electricity mix in 2030 and 2050 under each of the policy scenarios. Total electricity demand is reduced most significantly in both CAT50\% scenarios as the GHG price and/or mandated technology adoption under regulation raises the marginal cost of electricity generation, leading to a reduction in total electricity demand.

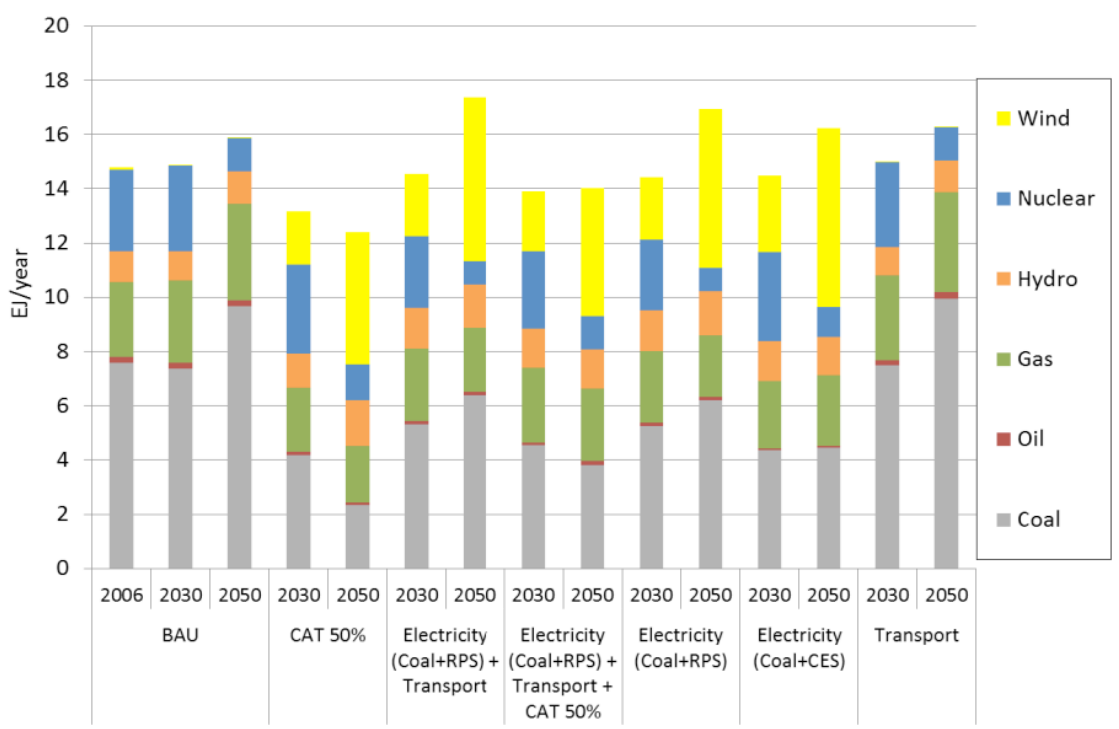

Figure 5. U.S. electricity generation mix by 2030 and 2050.

The regulatory policies have mixed effects. The "Coal+RPS" and "Coal+CES" policies produce similar outcomes - a difference is that coal is reduced less in the RPS case in part 
because the policy is less stringent relative to the CES policy by 2050 . The role of nuclear in the electricity sector declines in all cases between 2030 and 2050, as existing capacity is assumed in our model to be phased out amid a lack of public policy support for new construction. Wind electricity plays an important role in all scenarios that target the electricity sector, largely at the expense of coal. Natural gas continues to play a significant role in all policies, while the little remaining oil use in electricity is reduced under all policies (except for transport).

For the nation as a whole, electricity prices (shown in Figure 6) increase most under a capand-trade policy, as the emissions price is reflected in the cost of electricity generation. An electricity policy only results in modest price increases as power producers shift to mandated and more costly generating technologies to comply with policy, and the reductions required by the electricity policies modeled here prove to be smaller than under a cap-and-trade system. In the scenario that combines the cap-and-trade system and regulatory policies, the electricity price does not rise as much as it would under a cap-and-trade system alone. This is because the regulatory policies achieve some of the abatement that would otherwise need to be induced by a carbon price signal. In other words, because regulatory policies already require significant reductions through mandated technology changes, the sectoral burden of emissions reductions shifts, with electricity contributing only $34 \%$ of total reductions, relative to $44 \%$ under a cap and trade system with no regulatory policies. The price needed to achieve the balance of reductions will inevitably be lower.

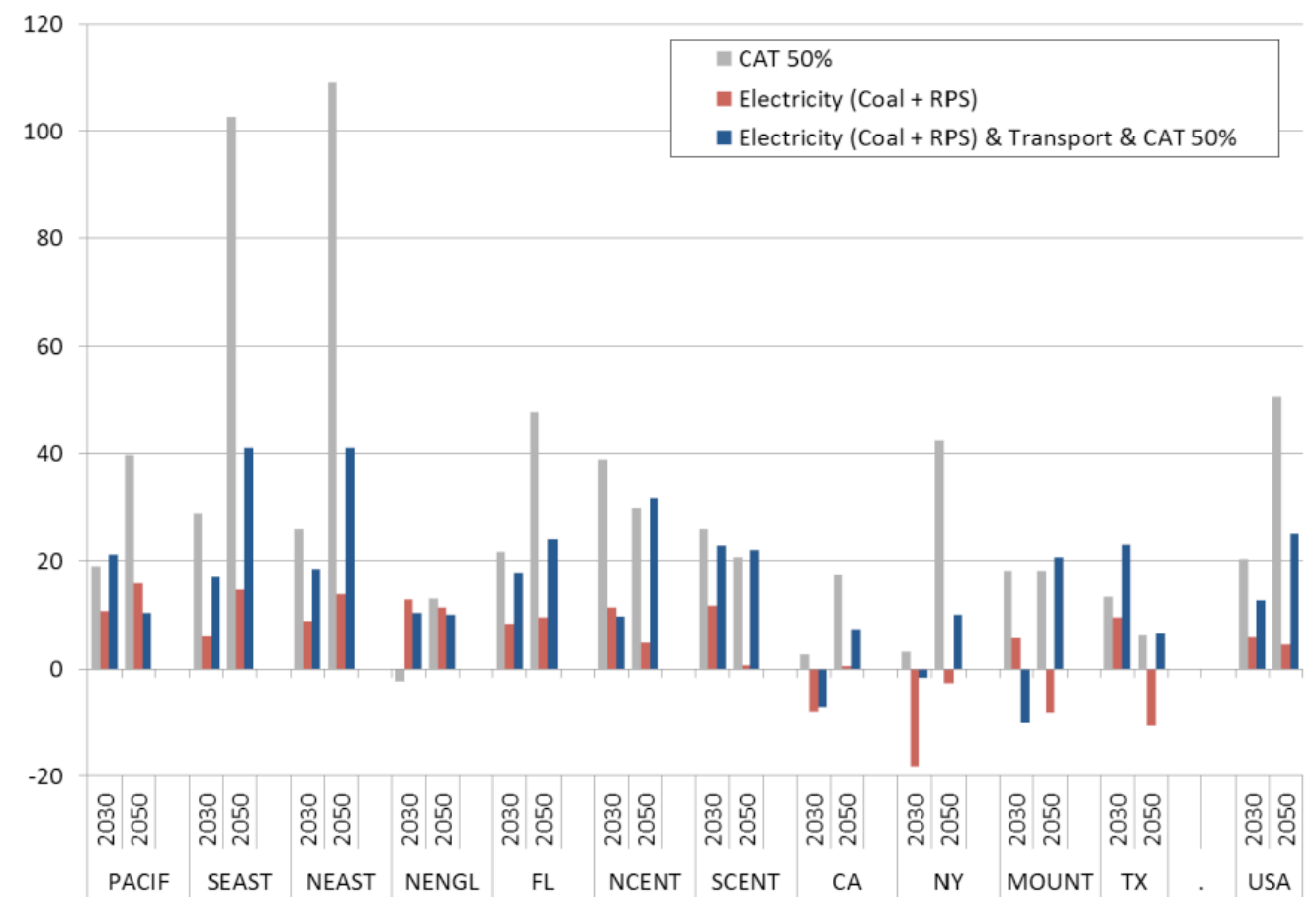

Figure 6. Percentage change in electricity price by region (relative to "business-as-usual").

\subsection{Welfare Impact by Region and Income Category}

National welfare impacts and aggregate technology and emissions responses can mask significant regional variation. The regional incidence of policy can be an important determinant 
of policy support, and a detailed understanding of incidence can help to inform design of policy that addresses equity as well as efficiency concerns.

To explain variation in the welfare impacts across these categories, we consider existing regional heterogeneity and detailed model forecasts of energy system characteristics under each policy scenario, and link changes in welfare to changes to energy prices, changes in the electricity mix, and region and income-specific electricity demand, vehicle ownership, and travel patterns.

\subsubsection{Regional Welfare Impact}

Table 5 summarizes the regional welfare cost expressed in both percentage of full income and in annual dollars per household. We find significant variation in costs across regions, which is reflected in the regional availability and cost effectiveness of abatement strategies. Comparing the cap-and-trade policy (CAT50\%) with and without the regulatory policies, the per-household annual welfare impacts are larger and more negative under the combined policy case in every region except for the Texas and Mountain regions, which benefit from abundant and costeffective wind resources. Within individual regions, there is not an additive relationship in welfare change across any of the policies considered here.

Table 5. Net present value of equivalent variation of income by region.

\begin{tabular}{|c|c|c|c|c|c|c|c|c|c|c|c|c|}
\hline & \multicolumn{2}{|c|}{ CAT $50 \%$} & \multicolumn{2}{|c|}{$\begin{array}{c}\text { Electricity } \\
\text { (Coal+RPS) }\end{array}$} & \multicolumn{2}{|c|}{$\begin{array}{c}\text { Electricity } \\
\text { (Coal+RPS) } \\
+ \text { Transport } \\
\end{array}$} & \multicolumn{2}{|c|}{ Transport } & \multicolumn{2}{|c|}{$\begin{array}{c}\text { Electricity } \\
\text { (Coal+RPS) }\end{array}$} & \multicolumn{2}{|c|}{$\begin{array}{c}\text { Electricity } \\
\text { (Coal+CES) }\end{array}$} \\
\hline & $\%$ & $\$ / h h$ & $\%$ & $\$ / h h$ & $\%$ & $\$ / h h$ & $\%$ & $\$ / h h$ & $\%$ & $\$ / h h$ & $\%$ & $\$ / h h$ \\
\hline NY & 1.1 & 794 & 2.2 & 1601 & 2.3 & 1690 & 2.0 & 1479 & 0.4 & 307 & 0.7 & 552 \\
\hline SCENT & 1.1 & 707 & 1.3 & 788 & 1.9 & 1112 & 1.0 & 479 & 0.5 & 418 & 0.4 & 357 \\
\hline SEAST & 0.6 & 341 & 0.8 & 414 & 1.2 & 592 & 0.3 & 65 & 0.6 & 434 & 0.7 & 377 \\
\hline NEAST & 0.6 & 398 & 1.1 & 740 & 1.2 & 797 & 1.0 & 338 & 0.6 & 509 & 0.7 & 487 \\
\hline FL & 0.6 & 177 & 1.3 & 659 & 1.4 & 617 & 0.6 & 189 & 0.8 & 545 & 0.9 & 464 \\
\hline NCENT & 0.6 & 437 & 0.9 & 492 & 1.2 & 744 & 1.0 & 259 & 0.4 & 334 & 0.6 & 455 \\
\hline TX & 0.5 & 334 & 0 & 72 & 0.5 & 324 & -0.2 & -157 & 0.2 & 320 & 0.3 & 321 \\
\hline MOUNT & 0.4 & 252 & 0.6 & 103 & 0.9 & 229 & 1.0 & 235 & 0 & -36 & 0.3 & 207 \\
\hline CA & 0.2 & 82 & 1.0 & 593 & 1.0 & 549 & 0.9 & 562 & 0.3 & 163 & 0.6 & 456 \\
\hline PACIF & 0.2 & 22 & 0.1 & 534 & 0.4 & 295 & 1.0 & 277 & -0.5 & -721 & 0 & -118 \\
\hline NENGL & -0.3 & -355 & 0.4 & 205 & 0.3 & 9 & 0.2 & 33 & 0.4 & 275 & 0.6 & 413 \\
\hline US & 0.5 & 307 & 0.9 & 510 & 1.1 & 615 & 1.0 & 308 & 0.4 & 305 & 0.6 & 386 \\
\hline
\end{tabular}

Note: Positive numbers show welfare losses; negative numbers show gains. NPV calculated using an annual discount rate of $4 \%$. "\%" refers to EV as percent of full income. " $\$ / \mathrm{hh}$ " refers to annual average of NPV of EV in $2005 \$$ per household.

The extent of effects can be quantified by evaluating the regional impacts of policies alone, in combination, and by comparison. For example, the sum of the welfare changes due to the transport and electricity (Coal+RES) policies individually does not equal the welfare change under the policies combined - in some regions, the welfare impact under the combined policies is less (better) than additive (e.g., New York), while in other regions welfare loss is larger (worse) than additive (e.g., South Central). 
Regional welfare impacts under the electricity policies can largely be explained by the region's starting grid mix and the cost and availability of clean alternatives (particularly wind), which are shown in Figure 7. Some regions are not strongly affected-regions with generally cleaner grids (California, New York, New England) need not undergo significant changes under any of the policy scenarios considered, and experience less welfare loss. Other regions, particularly those with substantial wind resources (Texas, South Central, North Central, Mountain), bring significant shares of wind generation online, largely at the expense of coal generation. The RPS policy, alone or in combination with a cap-and-trade policy, brings wind generation earlier to more regions where it is not economically viable under a cap-and-trade policy alone (California, Florida, and to some extent New York). In other regions, responses vary depending on the policy type and stringency, with electricity production in the Southeast and Northeast reduced substantially under a cap-and-trade system. However, these impacts are mitigated in a case where a RPS is combined with the cap. In the model new technologies face initial cost hurdles associated with ramping up production capacity and early stage development risks. Once these hurdles are overcome, cost-competitive technologies will be introduced into the new capital stock, assuming constant returns to scale. By encouraging early deployment of wind technology, low-cost wind capacity is available later on and can be scaled up without facing the large initial cost penalty in the period through 2050.
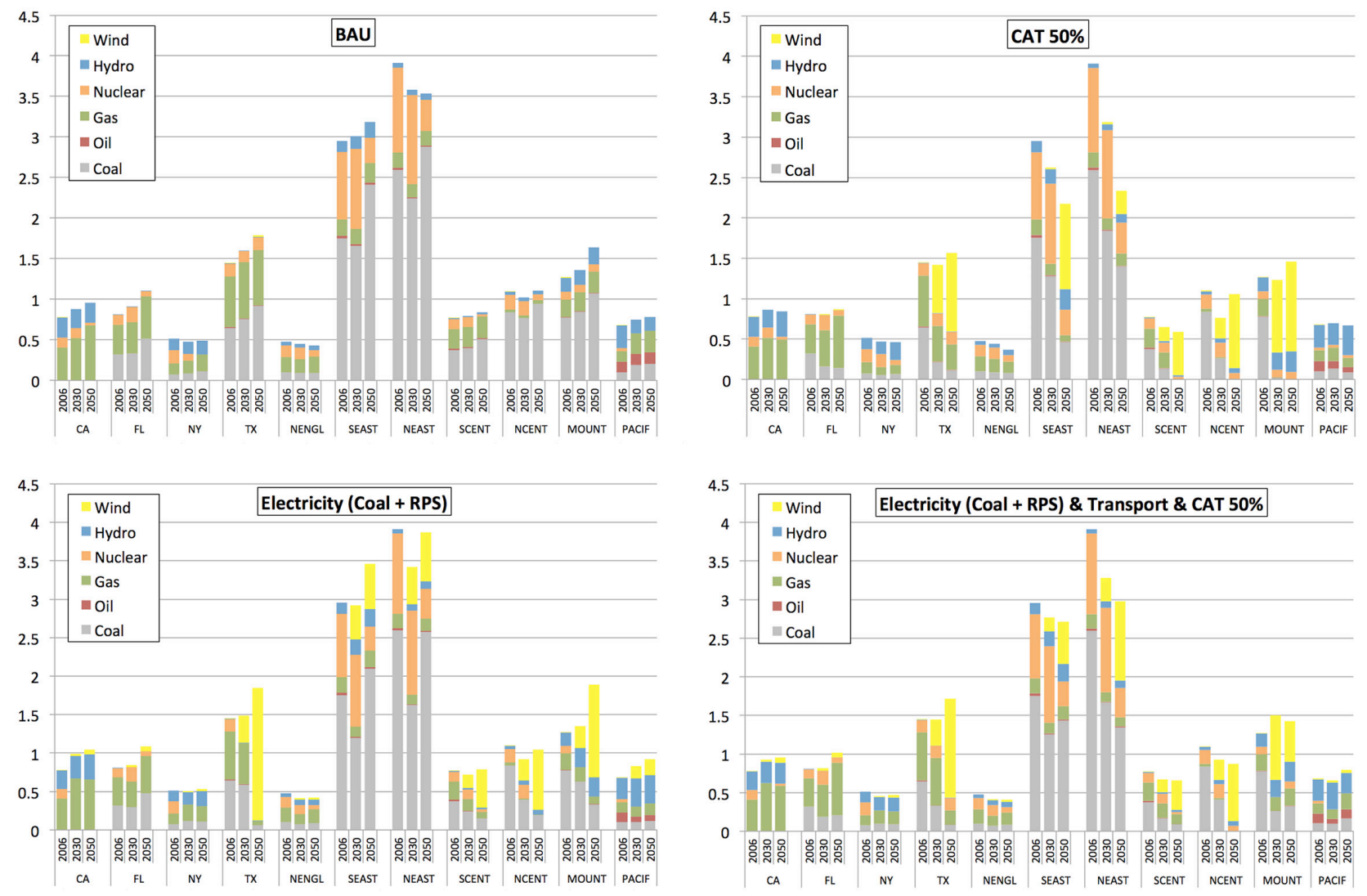

Figure 7. Regional electricity generation by source (EJ per year). 
The impetus for these responses is captured in the regional electricity prices that emerge under each policy scenario. The largest price increases occur in the Southeast and Northeast (over 100\% in 2050), while the electricity markets of New England and California are the least affected (in percentage terms). Different combinations of policies also produce regionally distinct price responses - a cap-and-trade system results in a decrease or very modest increase in electricity prices in New England and California, respectively, in 2030, reflecting each region's relatively clean grid mix. Electricity regulatory policies also result in only a modest price increase in these regions. However, in other regions (for instance, Southeast and Northeast) regulatory and market-based policies require significant changes in the grid mix relative to business-as-usual, which is reflected in electricity price increases that are much larger, particularly in the cap-and-trade policy scenario, as advanced electricity technologies remain costly in the absence of early deployment that would bring down costs over time.

To explain welfare losses associated with the transport policy, it is necessary to consider how the policy affects vehicle and fuel costs as they interact with diverse household preferences for vehicle ownership, efficiency and driving. As shown in Table 6, household expenditures devoted to vehicle transport as a percentage of total transport expenditures vary significantly across both regions and income categories. Regional differences can be related back to the local availability of alternatives to vehicle travel, as well as regional income, residential density, and road infrastructure, and are captured in the base year data set and initial share parameters.

Table 6. Mode shares and household expenditure share on vehicle transport (base year 2006).

\begin{tabular}{|c|c|c|c|c|c|c|c|c|c|c|}
\hline & \multicolumn{9}{|c|}{ Share of household miles traveled by household owned vs. purchased transport } & \multirow{3}{*}{$\begin{array}{c}\text { Average } \\
\text { share on } \\
\text { vehicle } \\
\text { transport }\end{array}$} \\
\hline & \multicolumn{9}{|c|}{ Income class } & \\
\hline & $<10$ & $10-15$ & $15-25$ & $25-30$ & $30-50$ & $50-75$ & $75-100$ & $100-150$ & $>150$ & \\
\hline CA & 74.2 & 78.6 & 84.8 & 72.8 & 87.7 & 80.7 & 82.9 & 84.6 & 80.3 & 4.9 \\
\hline FL & 82.8 & 85.9 & 85.8 & 78.9 & 91.4 & 87.2 & 90.6 & 89.8 & 86.8 & 9.6 \\
\hline NY & 52.8 & 75.3 & 75.9 & 66.0 & 84.2 & 79.5 & 80.3 & 82.8 & 78.6 & 11.5 \\
\hline$T X$ & 83.1 & 91.3 & 94.7 & 87.6 & 97.5 & 98.6 & 98.9 & 100.0 & 100.0 & 6.6 \\
\hline NENGL & 78.6 & 87.1 & 93.2 & 77.5 & 87.9 & 82.3 & 89.1 & 86.8 & 84.6 & 12.1 \\
\hline SEAST & 80.7 & 86.1 & 91.6 & 81.6 & 92.9 & 88.2 & 91.8 & 90.5 & 89.4 & 9.9 \\
\hline NEAST & 79.1 & 83.4 & 86.1 & 77.0 & 90.5 & 85.4 & 87.0 & 86.5 & 86.2 & 13.6 \\
\hline SCENT & 85.9 & 92.7 & 96.5 & 81.1 & 95.4 & 94.0 & 98.2 & 95.6 & 95.4 & 10.0 \\
\hline NCENT & 84.3 & 90.9 & 82.7 & 78.0 & 92.2 & 88.7 & 89.7 & 91.7 & 92.5 & 13.6 \\
\hline MOUNT & 74.2 & 87.8 & 92.0 & 76.9 & 92.4 & 86.9 & 92.9 & 89.9 & 90.2 & 12.0 \\
\hline PACIF & 84.0 & 94.8 & 79.8 & 72.0 & 87.8 & 83.6 & 90.3 & 82.7 & 84.0 & 11.7 \\
\hline U.S. & 6.2 & 8.4 & 10.5 & 6.3 & 13.0 & 10.2 & 12.8 & 12.1 & 11.1 & 10.8 \\
\hline
\end{tabular}

Note: Authors' own calculations based on U.S. Department of Transportation (2009). Average U.S. expenditure share on vehicle transport by income class.

When explaining welfare losses due to transport policy (shown in Table 5), it is important to recognize that the welfare loss is always expressed relative to the counterfactual, and so the degree of fuel efficiency improvement in the reference scenario is an important determinant of regional welfare loss under policy. Large welfare losses in New York (-2\%) can be explained by the fact that relative to the reference scenario, vehicles sold in New York must realize significant 
increases in fuel economy to achieve policy compliance. Given that a relatively large fraction of total passenger travel in New York does not occur in vehicles (47\% for lowest income category), an increase in fuel prices (which results from increasing resource scarcity) would also significantly affect energy demand by purchased modes, which are not covered under the policy. A fuel economy standard instead forces fuel conservation to be achieved through vehicle fuel efficiency, while use of refined oil in other sectors is indirectly subsidized. Significant welfare losses also occur in New England, North Central, Mountain, and Pacific States (all 1.0\%), given the large changes induced by the standard. Fuel economy improvement under the different policies is shown in Table 7. The table shows how the transport policy results in fuel economy improvements far in excess of those that occur with a cap-and-trade system as part of a comprehensive economy-wide GHG reduction program.

Table 7. New (zero to five years old) vehicle on-road fuel economy over time (miles per gallon).

\begin{tabular}{ll|llc|ccc|ccc}
\hline & Base & \multicolumn{3}{c|}{ BAU } & \multicolumn{3}{c|}{ Transport } & \multicolumn{3}{c}{ CAT 50\% } \\
\hline & 2006 & 2030 & 2050 & $\begin{array}{c}\text { Compound } \\
\text { annual } \\
\text { growth rate } \\
2006-2050\end{array}$ & 2030 & 2050 & $\begin{array}{c}\text { Compound } \\
\text { annual } \\
\text { growth rate } \\
2006-2050\end{array}$ & 2030 & $\begin{array}{c}\text { Compound } \\
\text { annual } \\
\text { growth rate } \\
2006-2050\end{array}$ \\
\hline CA & 23.2 & 24.0 & 25.0 & 0.17 & 31.1 & 43.7 & 1.45 & 24.6 & 26.2 & 0.27 \\
FL & 25.9 & 27.4 & 29.5 & 0.29 & 36.6 & 53.5 & 1.66 & 27.8 & 30.5 & 0.37 \\
MOUNT & 24.3 & 25.6 & 27.2 & 0.25 & 33.0 & 46.8 & 1.50 & 25.9 & 28.0 & 0.32 \\
NCENT & 23.8 & 24.7 & 25.9 & 0.20 & 31.6 & 43.8 & 1.40 & 25.1 & 26.7 & 0.27 \\
\hline NEAST & 23.4 & 24.2 & 25.1 & 0.16 & 31.5 & 43.9 & 1.44 & 24.7 & 26.2 & 0.25 \\
NENGL & 28.2 & 29.8 & 32.0 & 0.28 & 38.9 & 55.0 & 1.53 & 29.9 & 32.5 & 0.32 \\
\hline NY & 26.6 & 27.6 & 29.0 & 0.20 & 36.5 & 51.5 & 1.52 & 28.1 & 29.9 & 0.27 \\
PACIF & 23.2 & 23.8 & 24.7 & 0.15 & 30.5 & 42.0 & 1.36 & 24.3 & 25.7 & 0.24 \\
\hline SCENT & 23.5 & 24.5 & 25.7 & 0.21 & 32.3 & 46.2 & 1.55 & 25.0 & 26.9 & 0.31 \\
SEAST & 24.6 & 25.6 & 27.1 & 0.22 & 33.0 & 46.2 & 1.45 & 26.0 & 27.9 & 0.29 \\
\hline TX & 22.2 & 23.6 & 25.3 & 0.29 & 30.7 & 44.0 & 1.56 & 24.0 & 26.1 & 0.36 \\
\hline
\end{tabular}

Note: U.S. Department of Transportation (2009) and model forecast.

In all three policy scenarios, motor gasoline prices by region change significantly in 2030 relative to 2006. By raising the cost of gasoline proportional to carbon content, a cap-and-trade policy discourages refined oil use, leading to both lower price (net of the carbon charge) and demand. This downward price pressure is even stronger under the transport policy (fuel economy standard), because the transport policy displaces significantly more oil demand than the capand-trade system. While there is a relationship between the price change and the regional welfare loss, the price signal captures many potentially offsetting forces acting on the supplydemand balance, such as the household reliance on vehicle use, mode substitution potential, and different initial prices by region, and so price changes do not by themselves explain the welfare outcomes (see Figure 8). 


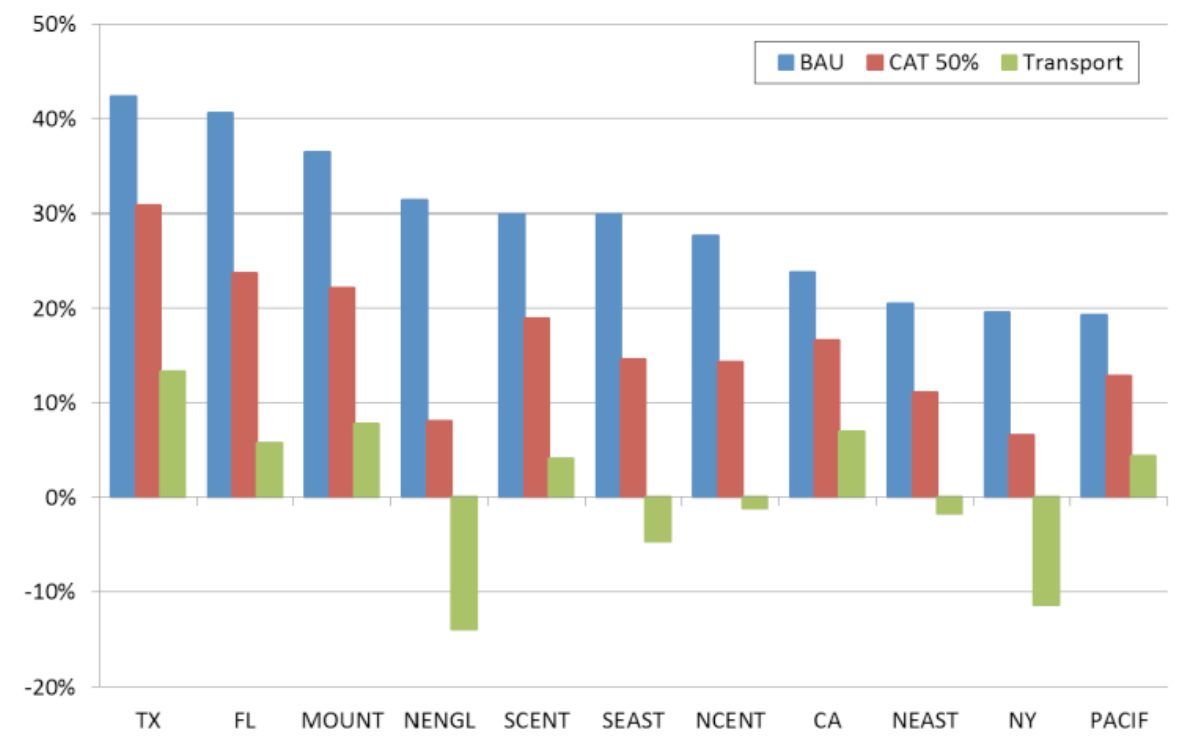

Figure 8. Percentage change in motor gasoline prices by region relative to 2006.

\subsubsection{Welfare Impact by Income Category}

An important question for policymakers is whether policies are regressive or progressive across income groups. We examine the impact of five of the above policies across nine income groups in the USREP model. We find the cap-and-trade and fuel economy policies to be moderately progressive, but the two electricity policies yield regressive welfare outcomes (see Figure 9). The results in the cap-and-trade case can be largely explained by the fact that revenue from the cap-and-trade policy is returned to households as a per-capita lump-sum transfer, while the owners of capital, concentrated in the higher income categories, must bear the costs of retrofitting or replacing capital to achieve policy compliance.

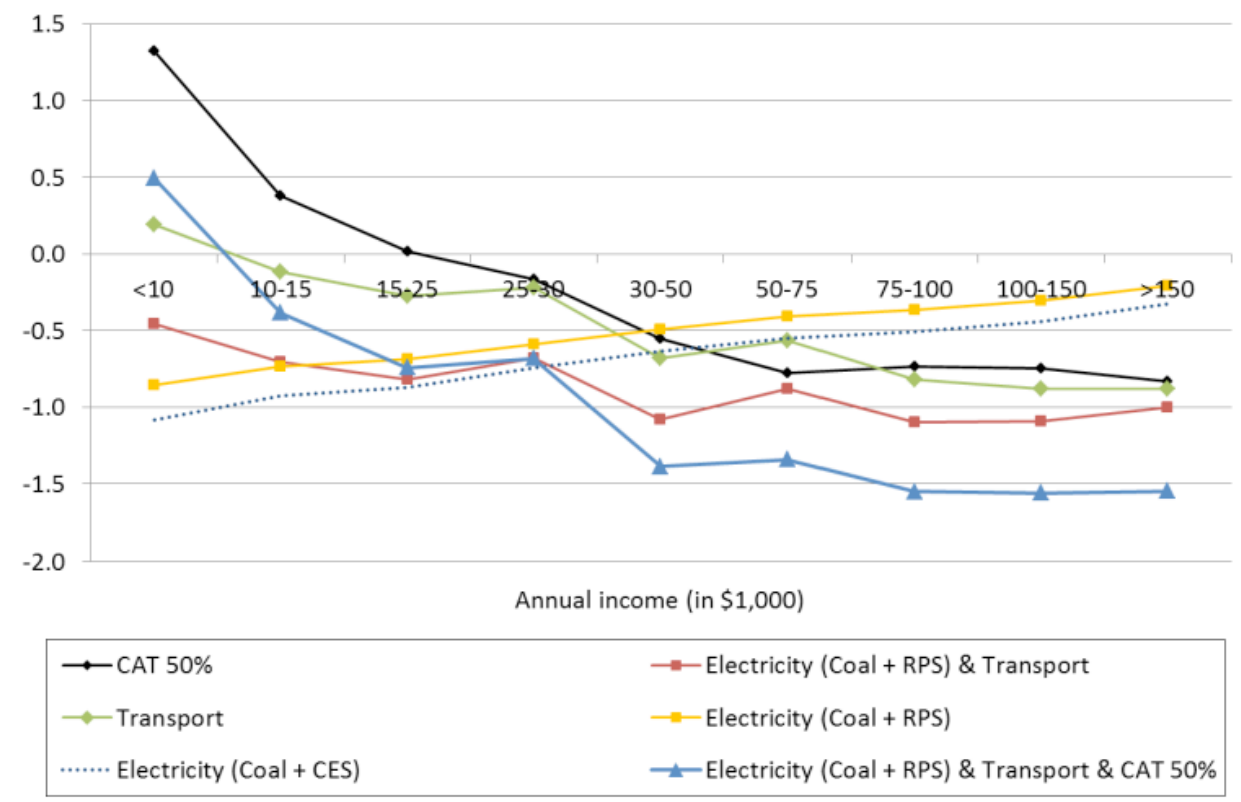

Figure 9. Percentage change in net present value of equivalent variation by income. 
Electricity policies have a regressive effect. Lower income households tend to spend a larger fraction of their budget on electricity for heating, cooking, and other residential use. If policy drives up electricity prices by imposing technology requirements on generation and distribution providers, the cost will be felt most acutely by low-income households. For a vehicle fuel economy standard, progressive welfare impacts are consistent with the intuition that many of the poorest households do not own vehicles or own used vehicles, which are not directly affected by the fuel economy standard (which focuses on new vehicles). The relative emphasis households in each region and income category assign to purchased relative to own-supplied (vehicle) modes is captured in Table 6, which also shows the average share of household expenditures on vehicle transport by region and income. Higher income households tend to own more vehicles and also drive them more. Households with higher incomes are also likely to include more members and thus to own more vehicles and travel more, leaving them potentially more affected by a vehicle price increases. With combined electricity and transport policies, low-income households shoulder a disproportionate burden of electricity policy costs, while wealthier households more acutely feel the impact of higher vehicle prices. The combined electricity and transport policy still yields a mildly progressive effect.

A comparison of the annual average net present value of welfare loss by income category under each of the policy scenarios is shown in Table 8.

Table 8. Per-household annual average of net present value of welfare cost by income group (in \$2005).

\begin{tabular}{lccccccc}
\hline $\begin{array}{c}\text { Annual } \\
\text { income } \\
\text { group } \\
\mathbf{\$ 1 , 0 0 0}\end{array}$ & $\begin{array}{c}\text { Fraction of } \\
\text { pop. (\%) }\end{array}$ & $\begin{array}{c}\text { CAT } \\
\mathbf{5 0} \%\end{array}$ & $\begin{array}{c}\text { Electricity } \\
\text { (Coal+RPS) } \\
\text { \& Transport }\end{array}$ & $\begin{array}{c}\text { Electricity } \\
\text { (Coal+RPS) } \\
\mathbf{8} \text { Transport } \\
\mathbf{8} \text { CAT 50\% }\end{array}$ & Transport & $\begin{array}{c}\text { Electricity } \\
\text { (Coal+RPS) }\end{array}$ & $\begin{array}{c}\text { Electricity } \\
\text { (Coal+CES) }\end{array}$ \\
\hline $\mathbf{< 1 0}$ & 7.3 & -546 & 162 & -188 & -63 & 314 & 357 \\
\hline $\mathbf{1 0 - 1 5}$ & 4.4 & -218 & 240 & 63 & 19 & 291 & 329 \\
\hline $\mathbf{1 5 - 2 5}$ & 9.5 & -95 & 285 & 180 & 54 & 312 & 354 \\
$\mathbf{2 5 - 3 0}$ & 9.8 & 79 & 318 & 238 & 71 & 338 & 389 \\
\hline $\mathbf{3 0 - 5 0}$ & 14.3 & 300 & 581 & 673 & 315 & 356 & 422 \\
\hline $\mathbf{5 0 - 7 5}$ & 19.9 & 598 & 549 & 805 & 327 & 336 & 426 \\
\hline $\mathbf{7 5 - 1 0 0}$ & 13.5 & 637 & 755 & 1034 & 555 & 318 & 432 \\
\hline $\mathbf{1 0 0 - 1 5 0}$ & 12.8 & 691 & 753 & 1076 & 642 & 239 & 369 \\
\hline $\mathbf{> 1 5 0}$ & 8.5 & 956 & 772 & 1261 & 778 & 136 & 281 \\
\hline All & 100 & 307 & 510 & 615 & 308 & 305 & 386 \\
\hline
\end{tabular}

Note: Positive numbers show welfare losses; negative numbers show gains. NPV calculated using an annual discount rate of $4 \%$.

\section{TOP-DOWN VS. BOTTOM-UP REPRESENTATION OF THE ELECTRICITY SECTOR}

The current research paradigm for ex-ante carbon policy assessment mainly involves two classes of models (see, e.g., Hourcade et al., 2006, for an overview). On one hand, technologyrich "bottom-up" models provide a detailed representation of generation technologies and the 
overall electricity system. On the other hand, economy-wide "top-down" models represent sectoral economic activities and electricity generation technologies through aggregate production functions. While these models are designed to incorporate general equilibrium effects, the use of smooth functions is not well-suited to capture the temporal and discrete nature of technology choice. $^{10}$

This section explores the implications of alternative structural models for the electricity sector. We compare two versions of USREP: a version that is based on a "top-down" representation of electricity - and that has been used for the analysis in the previous sections - with a version that features a detailed linear programming "bottom-up" load dispatch and capacity expansion model of the electricity sector. Our comparison focuses on the electricity-only policies, i.e. "Electricity (Coal+RPS)" and "Electricity (Coal+CES)".

While both modeling paradigms have been shown to produce similar results when focusing on conventional fossil-based electricity generating technologies, there exist significant differences in terms of how large-scale electricity generation from intermittent renewable energy sources is represented. We aim to obtain first insights into the question to what extent a relatively parsimonious "top-down" specification of the electricity sector can capture relevant key features of a structurally explicit "bottom-up" approach. ${ }^{11}$ More specifically, our analysis will focus on the following questions: How do both models compare in terms of electricity generation fuel mix? Do the models roughly agree with respect to the projected role of renewable energy under aggressive renewable energy policies for the electricity sector? How are electricity prices impacted? What are the implications for economic costs of decarbonizing the electricity sector both at the aggregate and regional level?

Our comparison is motivated by the fact that many modeling groups (e.g., USREGEN, NewEra, and ADAGE in this special issue) have recently undertaken substantial efforts to integrate a "bottom-up" electricity sector model within a large-scale CGE model. ${ }^{12}$ However, we

${ }^{10}$ In addition, top-down representations of the electricity sector violate basic energy conservation principles outside of the benchmark calibration point (see Sue Wing, 2008).

${ }^{11}$ Of course, if one is interested in model projections that provide very high resolution in terms of, for example, spatial, temporal, and technology dimensions, a detailed "bottom-up" approach may be more appropriate.

${ }^{12}$ The integration of bottom-up technology representation and economy-wide interactions into "hybrid" models is the subject of a large literature. For example, reference is often made to "soft-linked" models, where the combination of the two models either fails to achieve overall consistency (Hofman and Jorgenson, 1976; Hogan and Weyant, 1982; Drouet et al., 2005; Jacoby and Schäfer, 2006), or complements one type of model with a "reduced-form" representation of the other, thereby lacking structural explicitness (Messner and Schrattenholzer, 2000; Bosetti et al., 2006; Manne et al., 2006; Strachan and Kannan, 2008). An alternative and more recent approach, referenced to as "hard-linked", is to directly embed a set of discrete generation technologies into a topdown model (Böhringer, 1998; Sue Wing, 2006; Böhringer and Rutherford, 2008). Under this approach, however, the representation of technological detail significantly increases the dimensionality of the model, thus severely constraining large-scale applications. Finally, a decomposition algorithm by Böhringer and Rutherford (2008) employs an iterative solution procedure to solve top-down and bottom-up model components consistently. This approach is essentially a soft-linked approach, but overcomes issues of dimensionality and consistency, and has been employed in the context of U.S. climate policy in Sugandha et al. (2009) and Rausch and Mowers (2012). 
are not aware of any attempt in the literature that compares both modeling paradigms through a set of unified scenarios. While it is not possible to validate models used for ex-ante policy analysis, we believe that such a comparison can offer insights into the relative strengths and weaknesses of each approach.

\subsection{A “Top-Down" CGE Approach to Modeling Large-Scale Renewable Electricity Generation}

The top-down approach to modeling electricity generation in energy-economy CGE models involves a representative firm that minimizes production costs subject to technological, institutional and resource constraints. Electricity generation, as any other production activity, is typically described by a nested constant-elasticity-of-substitution (CES) function that combines energy, capital, labor and intermediate inputs from other sectors. The CES nesting structure for electricity generating technologies listed in Tables 2 and 3 is described in Paltsev et al. (2005).

Here, we provide a sketch of our approach to modeling electricity generated from wind energy. ${ }^{13}$ Using the "calibrated share form" (Rutherford, 1998), electricity generated by wind technology $n=\{$ Wind without backup, Wind with 100\% natural gas backup, Wind with 100\% biomass backup $\}$, at time $t$ in region $r, Y_{n, t, r}$, is in equilibrium determined by the following zeroprofit condition:

$$
\begin{aligned}
& p_{t, r} \geq\left\{\theta_{n, r}\left(\mu_{n, r} p_{n, w, t, r}\right)^{1-\sigma_{n, r}}+\left(1-\theta_{n, r}\right)\left(\mu_{n, r} p_{n, c, t, r}\right)^{1-\sigma_{n, r}}\right\}^{\frac{1}{1-\sigma_{n, r}}} \\
& \perp y_{n, t, r} \geq 0
\end{aligned}
$$

where $p_{t, r}$ is the output price of electricity which is treated as a homogenous commodity. $p_{n, c, t, r}$ is a CES price index of energy, capital, labor, and other inputs. $p_{n, w, t, r}$ denotes the price of a fixed factor wind resource, $\theta_{n, r}$ denotes the benchmark value share of the fixed factor and $\sigma_{n, r}$ is the elasticity of substitution between the resource and non-resource inputs.

It can be shown that the own-price price elasticity of electricity supply generated from wind using technology $n, E_{n, r}$ is related to $\theta_{n, r}$ as follows (assuming a stable price for variable factors, i.e. $\left.p_{n, c, t, r} \equiv 1\right)$ :

$$
E_{n, r}=\frac{\partial \log Y_{n, r}}{\partial \log p_{r}}=\sigma_{n, r} \frac{1-\theta_{n}}{\theta_{n}}
$$

\footnotetext{
${ }^{13}$ A similar logic could be applied to represent electricity generation from any other intermittent renewable energy source.
} 
$\mu_{n, r}$ is a multiplicative mark-up factor that describes the cost of the first MWh of wind generated with technology $n$ relative to a benchmark electricity generating technology, i.e. pulverized coal.

The resource input, $R_{n, r, t}$, is technology-specific, and is in fixed supply for any given period. Observations on penetration rates for new technology typically show a gradual penetration, for which there are numerous contributing factors. USREP replicates the penetration behavior that is typically observed by endowing each regional economy with a small amount of a specialized wind resource. The endowment of this resource grows as a function of output $Y_{n, r, t}$ in the previous period:

$$
R_{n, r, t+1}=f\left(Y_{n, r, t}, R_{n, r, t}, R_{n, r, 0}\right)
$$

Capacity expansion is thus constrained in any period by the amount of this fixed factor resource and the ability to substitute other inputs for it. As electricity generation from wind expands over time the endowment is increased, and it eventually is not a significant limitation on capacity expansion.

To characterize the wind resource by USREP region, we need to estimate for each region a pair $\left(\sigma_{n, r}, \mu_{n, r}\right)$. We use high-resolution wind data from NREL's Wind Integration Data sets (NREL, 2010) providing capacity factors and maximum output for wind turbines if they were located at sites across the U.S. ${ }^{14}$

For each potential wind site $i$, we execute a levelized cost of electricity model, described in Morris et al. (2010), that calculates the levelized cost of electricity of using technology $n$ on that site, $L C O E_{n, r, i}$. Based on an own-price elasticity formulation we use ordinary least-squares to fit:

$$
\log \left(q_{n, r, i}\right)=\alpha+E_{n, r} \log \left(L C O E_{n, r, i}\right)+v_{n, r, i} \text { if } i \in r
$$

where $q_{n, r, i}$ is electricity output, $\alpha$ is the estimated intercept, and $v_{n, r, i}$ is an error term. The logarithmic formulation means that the estimated coefficient $E_{n, r}$ is a (constant) price elasticity of supply. Exploiting the relationship in Eq. (2), we can incorporate estimated wind supply curves into the model.

The technology-specific markup-up factor is then given by:

$$
\mu_{n, r}=\frac{L \operatorname{COE}_{n, r, m i n}}{L C O E_{\text {bench }}}
$$

where $L C O E_{n, r, \text { min }}$ and $L C O E_{\text {bench }}$ denote the LCOE for the least-cost wind site and the benchmark electricity generating technology, respectively.

\footnotetext{
${ }^{14}$ Identified sites take into account land use restrictions and make particular assumptions about turbine technology and density of turbine placements. The data set includes on- and offshore wind sites.
} 
This deliberately simple approach is not without drawbacks. It has to rely on a strong assumption about backup capacity for non-dispatchable renewable electricity generating technology. Marcontonini and Parsons (2010) point out that LCOE is not an appropriate metric for comparing the economics of renewable generation with the economics of non-renewable generation technologies that are dispatchable. An implicit assumption behind the LCOE is that each generation technology is designed to produce base-load power. The solution to this problem adopted in USREP is to evaluate a synthetic base-load technology created by combining wind generation capacity together with $100 \%$ of backup capacity, so that the combination is able to be dispatched and a base-load profile of production can be assured. The upshot of this approach is that it provides only an upper bound on the economic cost of renewable technologies implying that the renewable technology is at least as economic as will be evidenced by an LCOE incorporating backup generation.

To partially address the issue of potentially overestimating the backup cost of wind at lower penetration levels, we include wind without backup technology. Electricity generated from this technology is limited by employing a supply schedule that fits a constant elasticity supply curve through the following two points: (i) the least cost wind site, and (ii) the cost for generating electricity with the wind with natural gas backup technology at a level that corresponds to $5 \%$ of current levels of electricity generation in a given region. The "effective" supply curve of wind represented in the model is thus a combination of wind electricity generated with $0 \%$ backup at lower output levels and with 100\% (natural gas) backup at higher output levels.

Despite this flexibility, the fundamental shortcoming of the "top-down" approach - positing that wind electricity at large scales can only be generated with a $100 \%$ backup capacity — still persists. While a more elaborated approach is likely to find that less than $100 \%$ backup is needed, it has to make explicit the system costs associated with high penetration levels of wind including transmission and distribution costs, end-user/storage costs, and costs imposed by meeting various reserve requirements.

\subsection{Integrating a "Bottom-up" Electricity Model in a CGE Framework: The USREP- ReEDS Model}

The "bottom-up" version of the electricity sector is based on the National Renewable Laboratory's ReEDS (Renewable Energy Deployment System) model (Short et al., 2009). ReEDS is a linear programming model that simulates the least-cost expansion of electricity generation capacity and transmission in the contiguous U.S. ReEDS provides a means of estimating the type and location of conventional and renewable resource development, the transmission infrastructure expansion requirements of those installations, the composition and location of generation, storage, and demand-side technologies needed to maintain system reliability.

ReEDS provides a detailed treatment of electricity generating and electricity storage technologies, and specifically addresses a variety of issues related to renewable energy technologies, including accessibility and cost of transmission, regional quality of renewable resources, seasonal and diurnal generation profiles, variability and non-dispatchability of wind and solar power, and the influence of variability on curtailment of those resources. ReEDS 
addresses these issues through a highly discretized regional structure, temporal resolution, explicit statistical treatment of the variability in wind and solar output over time, and consideration of ancillary services requirements and costs.

Rausch and Mowers (2014) embed the ReEDS model within the general equilibrium framework underlying the USREP model by employing a block decomposition algorithm put forward by Böhringer and Rutherford (2008). The virtue of this integrated approach is that electric-sector optimization - comprising electricity supply and demands for fuels, capital, labor and other inputs - is fully consistent with the equilibrium response of the macro-economic system - comprising electricity demand, fuel prices, and goods and factor prices). More details on the integrated top-down electricity model can be found in Rausch and Mowers (2014).

\subsection{Model Comparison}

Table 9 compares welfare costs, cumulative $\mathrm{CO}_{2}$ emissions, and electricity price impacts obtained from the two alternative electricity models for each respective electricity-sector policy. Focusing first on the CES policy, the comparison suggests that both models produce roughly comparable net present value (NPV) welfare costs at the aggregated level. USREP with a "topdown" formulation of electricity estimates that NPV welfare costs of a federal CES policy are US\$ trillion 2.08 whereas the USREP-ReEDS model suggests slightly lower costs at US\$ trillion 1.97. Both models somewhat disagree on the amount of cumulative economy-wide $\mathrm{CO}_{2}$ emissions reductions over the 2012-2050 period with the USREP-ReEDS model projecting about $16 \mathrm{Gt}$ or about $50 \%$ higher emissions reductions. This can be explained by differences in the electricity generation mix shown in Figure 10. By 2050, the USREP-ReEDS forecasts that almost all coal generation capacity will have retired or be idle and a substantial fraction of electricity is generation from nuclear power; in the model with a "top-down" electricity sector, the expansion of nuclear is limited by a nuclear phase-out constraint that is part of the scenario assumptions of the EMF24 study.

Table 9. Model comparison of key variables.

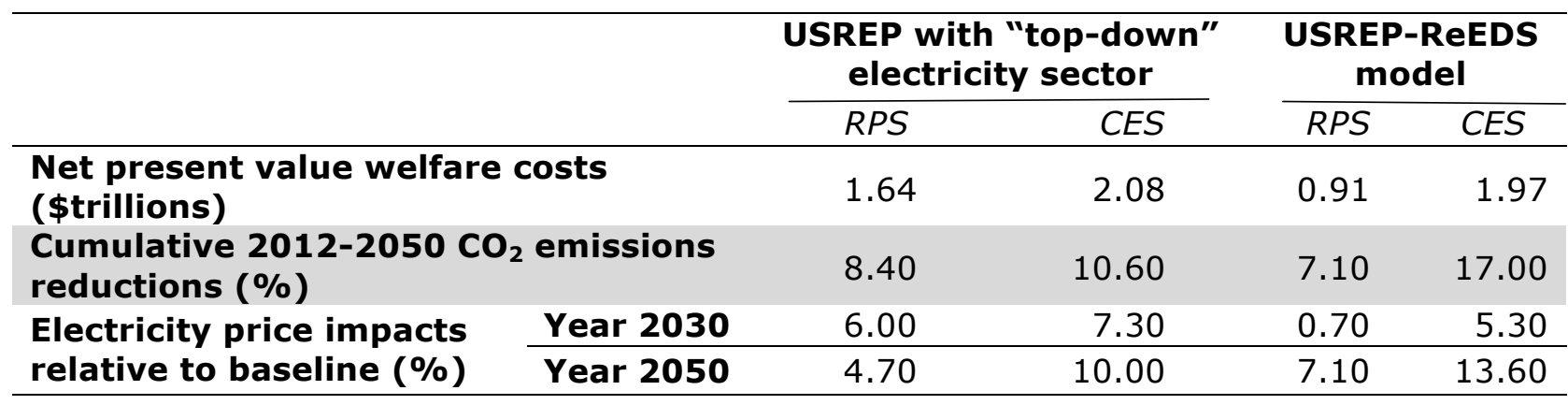

Comparing electricity generation from renewable sources, it should be noted that the simplified "top-down" model only considers wind and biomass, while the USREP-ReEDS model includes all major renewable energy technologies including utility-scale photovoltaics (PV), concentrated solar power (CSP), and geothermal. These are represented by the category "other renewables" in Figure 10. While the USREP-ReEDS model suggests slightly higher deployment 
of wind and other renewables in 2030, both models largely agree in 2050 , with the "top-down" approach suggesting a level of wind energy that is comparable to the sum of wind and other renewables projected by the USREP-ReEDS model. Electricity price impacts projected by the two models are similar with the USREP-ReEDS model yielding slightly higher price impacts relative to the BAU baseline (13.6\%) than the "top-down" model (10.0\%) in 2050.

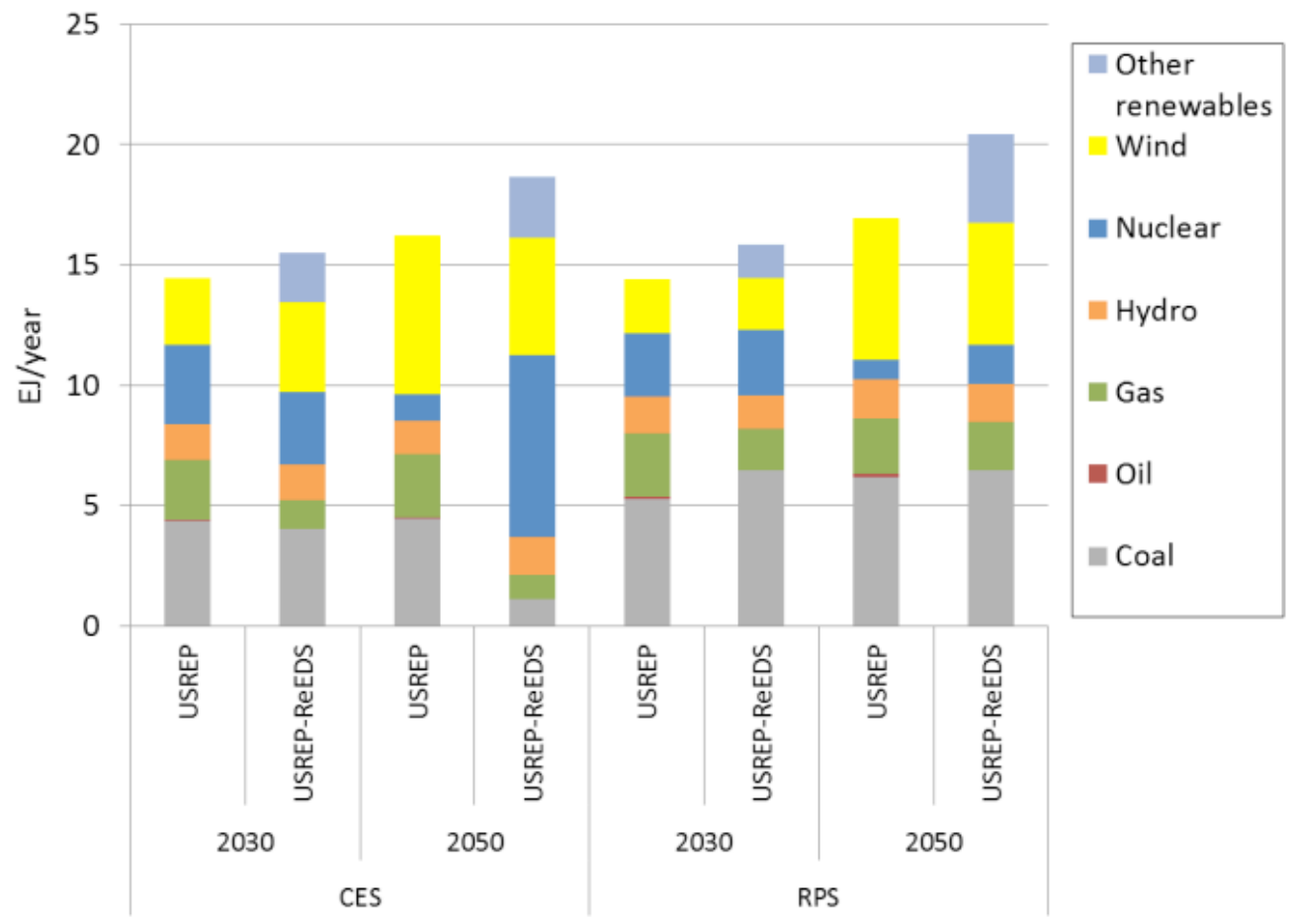

Figure 10. Model comparison of U.S. electricity generation by fuel.

Differences between the "top-down" and "bottom-up" approaches become more apparent if one focuses on the RPS policy as this instrument targets only renewable energy technologies and rules out that "clean" fossil-based technologies and nuclear power can be used to meet the energy standard. Figure 10 shows that both modeling approaches project very similar levels of electricity generation from non-renewable energy sources and hydro by 2030 and 2050. While the projected amounts of wind electricity are again similar under both approaches, other renewables - which are not included in the "top-down" approach-contribute about 3.5 EJ (out of 20 EJ of total electricity production) in 2050 under the "bottom-up" approach. The inclusion of additional flexibility to meet the RPS translates into significantly lower estimates of economic costs associated with the RPS policy: if the "bottom-up" approach is used, NPV welfare costs are $44 \%$ lower as compared to the "top-down" CGE representation. Finally, both models produce similar projections in terms of $\mathrm{CO}_{2}$ emissions reductions under the RPS policy case. Figure 11 compares the regional electricity generation mix by fuel across both models. Several points are worth noting.

First, while — not surprisingly — both approaches predict a somewhat different picture in terms of the regional electricity generation mix, for most regions the differences remain relatively 
small, thus being consistent with the fact that national-level results have been found to be largely similar. Focusing on electricity from wind only, relatively large disagreements between both models only exist for the NCENT region in 2030 and for the NEAST, NCENT and TX regions in 2050. Second, other non-wind renewables play a relatively modest role - with the exception of CA which deploys significant amount of geothermal and solar power in the USREP-ReEDS model by 2050 - in terms of the electricity generation mix (not for costs as was noted above). Third, both models are relatively similar by 2030 but differences are more pronounced in 2050 . Fourth, both models also produce a somewhat different picture in terms of fossil-based electricity generation among regions.
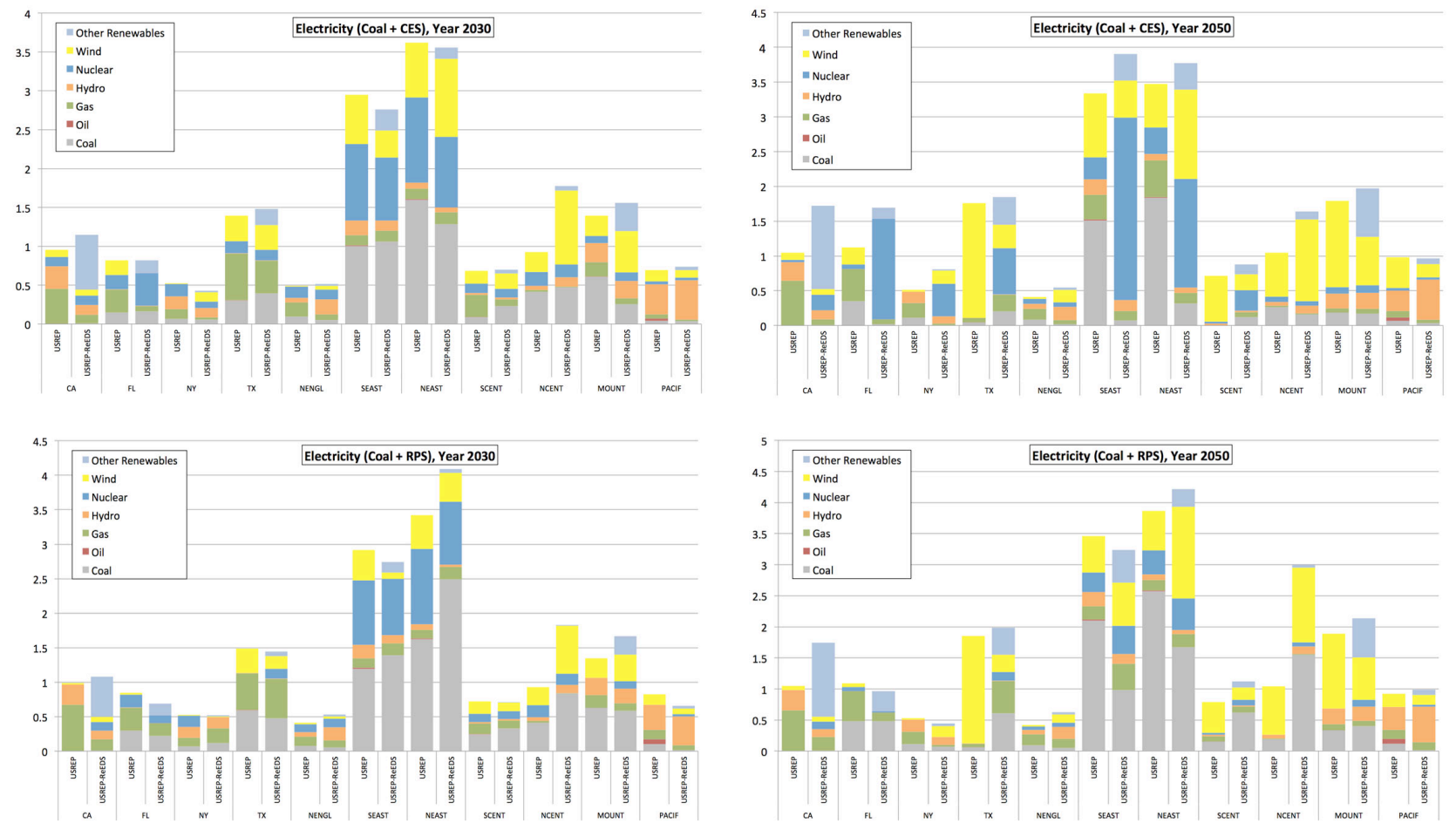

Figure 11. Model comparison of regional electricity generation by fuel.

In summary, we conclude that the "top-down" approach produces very similar national-level welfare costs and electricity generation mix for the CES policy compared to the more tailored "bottom-up" approach. Discrepancies among both approaches for the RPS policy case are largely due to the fact that the "top-down" model does not consider other, non-wind renewable energy technologies. These could be easily added to the model following a similar approach as for wind, and would therefore likely bring cost estimates from both approaches more in line. At the regional level, the two approaches are largely consistent in terms of where significant investments in wind capacity/generation will occur. For a few regions, projections across both approaches yield discrepancies with respect to the electricity generation mix suggesting that a simplified "top-down" approach does not adequately describe the relevant "bottom-up" constraints in these regions. 
We believe that this exercise has provided some first evidence that a parsimoniously specified "top-down" approach to modeling electricity generation can provide results that are, at least at the aggregated level, consistent with those obtained from a structurally more explicit "bottomup" approach. As this depends on how well the responses of a CGE model would be calibrated to those from a bottom-up model, one can of course not generalize this finding to any generic topdown model. However, this rebuts to some extent the criticism put forward by modelers arguing that the lack of detail in "top-down" CGE models to represent critical features of the power system, especially with respect to large-scale intermittent renewable electricity generation, makes these models an inappropriate tool to study these issues.

\section{CONCLUSIONS}

This paper has investigated both the efficiency and distributional impacts of a representative set of climate policy scenarios under consideration in the United States, developed as part of the EMF24 modeling exercise. This paper moves beyond the canonical result that market-based instruments produce superior welfare outcomes to examine in detail the distributional impacts of a range of policy options. We apply an empirically-calibrated model of the U.S. economy with disaggregated regions and income categories, and with a rich description of the energy system including advanced technology detail. We further include a sensitivity analysis that provides initial evidence of the robustness of model outputs to the inclusion of technology and market detail at various levels of resolution.

The market-based instrument we model, a cap-and-trade system, yields superior welfare outcomes and also provides an effective mechanism for reducing the distributional impacts. The cost advantage can be directly traced to abatement flexibility across gases, sectors, technologies, and time, and is reinforced by the ability to recycle revenues as lump-sum transfers to households on a per-capita basis. Relative to a cap-and-trade system, regulatory policies are highly constrained in terms of the abatement opportunities available and the time frame on which these opportunities can be pursued. Even if limited flexibility provisions are added to regulatory policies, low cost opportunities are still limited by the policy scope. A fuel economy policy for new light-duty vehicles that introduces credit trading across manufacturers and extends banking and borrowing provisions will not change the fact that petroleum or emissions can only be reduced through measures that raise vehicle efficiency. The marginal costs of reducing electricity or transport emissions quickly exceed the marginal cost of reductions that would be incentivized under an equivalent cap-and-trade system. The flexibility and revenue redistribution potential under a cap-and-trade policy is a powerful advantage.

Regional variation in welfare impacts is significant, both across regions for a given policy and across different policies. Our results suggest that welfare impacts are more evenly spread under the cap-and-trade policy, given that reductions are spread across many sectors and as such do not unduly burden regions based on their relative advantages and disadvantages in terms of abatement costs and opportunities. Revenue recycling also helps to reduce burdens across all regions in the cap-and-trade case. By contrast, some regions are limited in their ability to respond 
to mandates that require action by sector or technology and thus face high costs, if these policies encourage costly reductions that would not have otherwise been pursued. This analysis underscores that regulatory policies can exaggerate the difference between winners and losers, by focusing on action in particular sectors or technologies and sparing others, while a cap-andtrade system calls forth action (albeit perhaps less aggressive) from across the economy and energy system.

In terms of variation in policy impact across income groups, our analysis finds that an electricity policy is regressive, while transport and cap-and-trade policies are moderately progressive. It is plausible that a transport policy (the only one of the policies we consider that is currently implemented at the national level) may be politically attractive because of its progressive nature and the fact that it exerts downward pressure on gasoline prices. These price reductions hide the true cost to households of efficiency improvements required, and improved fuel efficiency encourages consumers to drive more rather than less. Evidence of the regressive nature of electricity policies, by contrast, may discourage their broader acceptance.

\section{Acknowledgements}

We acknowledge support of the MIT Joint Program on the Science and Policy of Global Change through a combination of government, industry, and foundation funding, the MIT Energy Initiative, and additional support for this work from a coalition of industrial sponsors. This work is also supported by the DOE Integrated Assessment Grant (DE-FG02-94ER61937). For development of the USREP-ReEDS model, the authors further acknowledge the support of the Joint Institute for Strategic Energy Analysis, which is operated by the Alliance for Sustainable Energy, LLC, on behalf of the U.S. Department of Energy's National Renewable Energy Laboratory, the University of Colorado-Boulder, the Colorado School of Mines, the Colorado State University, the Massachusetts Institute of Technology, and Stanford University.

\section{REFERENCES}

Armington, P., 1969: A Theory of Demand for Products Distinguished by Place of Production, International Monetary Fund Staff Papers, 16: 159-76.

Böhringer, C., 1998: The Synthesis of Bottom-Up and Top-Down in Energy Policy Modeling, Energy Economics, 20: 233-248.

Böhringer, C. and T.F. Rutherford, 2008: Combining Bottom-up and Top-down, Energy Economics, 30(2): 574-596.

Bosetti, V., C. Carraro, M. Galeotti, E. Masesetti and M. Tavoni, 2006: WITCH: A World Induced Technical Change Hybrid Model, Energy Journal, 27(Special Issue).

Bovenberg, A.L. and L.H. Goulder, 1996: Optimal Environmental Taxation in the Presence of Other Taxes: General Equilibrium Analyses, American Economic Review, 86: 985-1000.

Davidson, M.D. and H.P. van Essen., 2009: EU Transport GHG: Routes to 2050? Methodological Issues Related to Assessing Cost Effectiveness of Climate Change Abatement Options, EU Transport GHG 2050: Bussels, Belgium.

DOE (U.S. Department of Energy), 2009: U.S. Crude Oil, Natural Gas, and Natural Gas Liquids Reserves, 1977 through 2007. 
Drouet, L., A. Haurie, M. Labriet, P. Thalmann, M. Vielle and L. Viguier, 2005: A Coupled Bottom-Up/Top-Down Model for GHG Abatement Scenarios in the Swiss Housing Sector, in Energy and Environment, R. Loulou, J. P. Waaub, and G. Zaccour (eds.), 27-62.

Cambridge University Press.

Dyni, J.R., 2006: Geology and Resources of Some World Oil-Shale Deposits.

EIA, Energy Information Administration, 2009: State Energy Data System.

EPA, US Environmental Protection Agency, 2009: Inventory of U.S. Greenhouse Gas Emissions and Sinks: 1990-2007.

Fawcett, A.A., L.C. Clarke, S. Rausch and J.P. Weyant, 2014: Policy Overview of EMF 24 Study, Energy Journal, forthcoming.

Feenberg, D. and E. Coutts, 1993: An Introduction to the TAXSIM Model, Journal of Policy Analysis and Management, 12(1).

Fischer, C. and L. Preonas, 2010: Combining Policies for Renewable Energy: Is the Whole Less Than the Sum of Its Parts?

Goulder, L.H., I.W.H. Parry and R.C. Williams III, 1999: The Cost-effectiveness of Alternative Instruments for Environmental Protection in a Second-best Setting, Journal of Public Economics 72, 329-360.

GTAP (Global Trade Analysis Project), 2008: Global Trade, Assistance, and Production: The GTAP 7 Data Base, G.B. Narayanan and T.L. Walmsley (eds). Center for Global Trade Analysis, Purdue University (http://www.gtap.agecon.purdue.edu/databases/v7/v7_doco.asp).

Harberger, A.C., 1964: Taxation, Resource Allocation and Welfare, in: The Role of Direct and Indirect Taxes in the Federal Reserve System. Princeton University Press: Princeton, New Jersey.

Hofman, K. and D. Jorgenson, 1976: Economic and Technological Models for Evaluation of Energy Policy. The Bell Journal of Economics, 8(2): 444-446.

Hogan, W. and J.P. Weyant, 1982: Combined Energy Models, in: Advances in the Economics of Energy and Resources, J. R. Moroney (ed.), 117-150. JAI Press.

Hourcade, J.-C., M. Jaccard, C. Bataille and F. Ghersi, 2006: Hybrid Modeling: New Answers to Old Challenges, Energy Journal, 27(Special Issue): introduction.

Hyman, R.C., J.M. Reilly, M.H. Babiker, A.V. de Masin and H.D. Jacoby, 2002: Modeling Non$\mathrm{CO}_{2}$ Greenhouse Gas Abatement, Environmental Modeling and Assessment, 8(3): 175-186.

IMPLAN (Minnesota IMPLAN Group), 2008: State-Level U.S. Data for 2006.

Karplus, V.J., S. Paltsev, M. Babiker and J. M. Reilly, 2013a: Combining a New Vehicle Fuel Economy Standard with a Cap-and-Trade Policy: Energy and Economic Impact in the United States, Energy Economics, 36: 322-333.

Karplus, V.J., S. Paltsev, M. Babiker and J.M. Reilly, 2013b: Applying Engineering and Fleet Detail to Represent Passenger Vehicle Transport in a Computable General Equilibrium Model, Economic Modelling, 30: 295-305.

Lindall, S., D. Olson and G. Alward, 2006: Deriving Multi-Regional Models Using the IMPLAN National Trade Flows Model, Paper Delivered at the 1998 Regional Science Association International Meeting in Sante Fe, New Mexico, 36(1): 76-83.

Manne, A., R. Mendelssohn and R. Richels, 2006: MERGE: A Model for Evaluating Regional and Global Effects of GHG Reduction Policies, Energy Policy, 23: 17-43. 
Marcontonini, C. and J.E. Parsons, 2010: Synthesis Report on Other Studies of the Levelised Cost of Electricity. In: Projected Costs of Generating Electricity, International Energy Agency, Chapter 11, pp. 189-200.

Mathiesen, L. 1985: Computation of Economic Equilibria by a Sequence of Linear Complementarity Problems, Mathematical Programming Study, 23: 144-162.

Messner, S. and L. Schrattenholzer, 2000: MESSAGE-MACRO: Linking an Energy Supply Model with a Macroeconomic Model and Solving Iteratively, Energy-The International Journal, 25(3): 267-282.

Metcalf, G.E., 2009: Market-based Policy Options to Control U.S. Greenhouse Gas Emissions, Journal of Economic Perspectives, 23: 5-27.

Morris, J.F., J.M. Reilly, and S. Paltsev. 2010: Combining a Renewable Portfolio Standard with a Cap-and-Trade Policy: A General Equilibrium Analysis.

(http://globalchange.mit.edu/files/document/MITJPSPGC_Rpt187.pdf).

NREL (National Renewable Energy Laboratory), 2010: Wind Integration Data Sets.

Oakridge National Laboratories, 2009: Estimated Annual Cumulative Biomass Resources Available by State and Price (http://bioenergy.ornl.gov).

Paltsev, S., J.M. Reilly, H.D. Jacoby, R.S. Eckhaus, J. McFarland, M. Sarofim, M.O. Asadoorian and M.H. Babiker, 2005: The MIT Emissions Prediction and Policy Analysis (EPPA) Model: Version 4, MITJPSPGC Report 125, August, 72 p.

(http://globalchange.mit.edu/files/document/MITJPSPGH_Rpt125.pdf).

Paltsev, S., J.M. Reilly, H.D. Jacoby and J.F. Morris, 2009: The Cost of Climate Policy in the United States, Energy Economics, 31: S235-S243.

Parry, I.W.H. and R.C. Williams III, 2011: Moving U.S. Climate Policy Forward: Are Carbon Taxes the Only Good Alternative? Resources for the Future: Washington, D.C. (http://www.rff.org/documents/RFF-DP-11-02.pdf).

Pethig, R. and C. Wittlich, 2009: Interaction of Carbon Reduction and Green Energy Promotion in a Small Fossil-fuel Importing Economy, CESifo Working Paper No. 2749, August, 29 p.

Rausch, S., G.E. Metcalf, J.M. Reilly and S. Paltsev, 2010a: Distributional Implications of Alternative U.S. Greenhouse Gas Control Measures, The B.E. Journal of Economic Analysis and Policy, 10(2).

Rausch, S., G.E. Metcalf, J.M. Reilly and S. Paltsev, 2010b: U.S. Energy Tax Policy, in Distributional Impacts of a U.S. Greenhouse Gas Policy: a General Equilibrium Analysis of Carbon Pricing, Gilbert E. Metcalf (ed.), Cambridge University Press: New York, Chapter 3, pp. 52-112.

Rausch, S. and M. Mowers, 2014: Distributional and Efficiency Impacts of Clean and Renewable Energy Standards for Electricity, Resource and Energy Economics, forthcoming.

Rausch, S. and T.F. Rutherford, 2008: Tools for Building National Economic Models Using State-Level Implan Social Accounts. (http://www.mpsge.org/IMPLAN2006inGAMS/IMPLAN2006inGAMS.pdf).

del Rio Gonzalez, P., 2007: The Interaction Between Emissions Trading and Renewable Electricity Support Schemes. An Overview of the Literature, Mitigation and Adaptation Strategies for Global Change, 12(8): 1363-1390.

Rutherford, T.F., 1995: Extension of GAMS for Complementarity Problems Arising in Applied Economics. Journal of Economic Dynamics and Control, 19(8): 1299-1324. 
Rutherford, T.F., 1998: Economic Equilibrium Modeling with GAMS: An Introduction to GAMS/MCP and GAMS/MPSGE (http://www.gams.com/dd/docs/solvers/mpsge.pdf).

Rutherford, T.F., 1999: Applied General Equilibrium Modeling with MPSGE as a GAMS Subsystem: An Overview of the Modeling Framework and Syntax, Computational Economics, 14: 1-46.

Schafer, A. and H.D. Jacoby, 2006: Vehicle Technology Dynamics Under $\mathrm{CO}_{2}$-constraint: A General Equilibrium Analysis. Energy Policy, 34(9): 975-985.

Short, W., P. Sullivan, T. Mai, M. Mowers, C. Uriate, N. Blair, D. Heimiller, and A. Martinez, 2011: Regional Energy Deployment System (ReEDS). (http://www.nrel.gov/analysis/reeds/pdfs/reeds_documentation.pdf)

Strachan, N. and R. Kannan, 2008: Hybrid Modelling of Long-term Carbon Reduction Scenarios for the UK, Energy Economics, 30(6): 2947-2963.

Sue Wing, I., 2006: The Synthesis of Bottom-Up and Top-Down Approaches to Climate Policy Modeling: Electric Power Technologies and the Cost of Limiting U.S. $\mathrm{CO}_{2}$ Emissions, Energy Policy, 34(18): 3847-3869.

Sue Wing, I., 2008: The synthesis of bottom-up and top-down approaches to climate policy modeling: Electric power technology detail in a social accounting framework, Energy Economics 30(2): 547-573.

Sugandha, T.D., M. Yuan, P. Bernstein, W.D. Montgomery and A. Smith, 2009: A Top-down Bottom-up Modeling Approach to Climate Change Policy Analysis. Energy Economics, 31(S2): S223-S234.

U.S. Department of Transportation, 2009: National Household Travel Survey.

USGS (U.S. Geological Survey), 2009: USCOAL Coal Resources Database. 


\section{REPORT SERIES of the MIT Joint Program on the Science and Policy of Global Change}

FOR THE COMPLETE LIST OF JOINT PROGRAM REPORTS: http://globalchange.mit.edu/pubs/all-reports.php

222. Modeling Water Withdrawal and Consumption for Electricity Generation in the United States Strzepek et al. June 2012

223. An Integrated Assessment Framework for Uncertainty Studies in Global and Regional Climate Change: The MIT IGSM Monier et al. June 2012

224. Cap-and-Trade Climate Policies with Price-Regulated Industries: How Costly are Free Allowances? Lanz and Rausch July 2012

225. Distributional and Efficiency Impacts of Clean and Renewable Energy Standards for Electricity Rausch and Mowers July 2012

226. The Economic, Energy, and GHG Emissions Impacts of Proposed 2017-2025 Vehicle Fuel Economy Standards in the United States Karplus and Paltsev July 2012

227. Impacts of Land-Use and Biofuels Policy on Climate: Temperature and Localized Impacts Hallgren et al. August 2012

228. Carbon Tax Revenue and the Budget Deficit: $\boldsymbol{A}$ Win-WinWin Solution? Sebastian Rausch and John Reilly August 2012

229. CLM-AG: An Agriculture Module for the Community Land Model version 3.5 Gueneau et al. September 2012

230. Quantifying Regional Economic Impacts of $\mathrm{CO}_{2}$ Intensity Targets in China Zhang et al. September 2012

231. The Future Energy and GHG Emissions Impact of Alternative Personal Transportation Pathways in China Kishimoto et al. September 2012

232. Will Economic Restructuring in China Reduce Trade Embodied $\mathrm{CO}_{2}$ Emissions? Qi et al. October 2012

233. Climate Co-benefits of Tighter $\mathrm{SO}_{2}$ and $\mathrm{NO}_{x}$ Regulations in China Nam et al. October 2012

234. Shale Gas Production: Potential versus Actual GHG Emissions O'Sullivan and Paltsev November 2012

235. Non-Nuclear, Low-Carbon, or Both? The Case of Taiwan Chen December 2012

236. Modeling Water Resource Systems under Climate Change: IGSM-WRS Strzepek et al. December 2012

237. Analyzing the Regional Impact of a Fossil Energy Cap in China Zhang et al. January 2013

238. Market Cost of Renewable Jet Fuel Adoption in the United States Winchester et al. January 2013

239. Analysis of U.S. Water Resources under Climate Change Blanc et al. February 2013

240. Protection of Coastal Infrastructure under Rising Flood Risk Lickley et al. March 2013

241. Consumption-Based Adjustment of China's EmissionsIntensity Targets: An Analysis of its Potential Economic Effects Springmann et al. March 2013

242. The Energy and $\mathrm{CO}_{2}$ Emissions Impact of Renewable Energy Development in China Zhang et al. April 2013
243. Integrated Economic and Climate Projections for Impact Assessment Paltsev et al. May 2013

244. A Framework for Modeling Uncertainty in Regional Climate Change Monier et al. May 2013

245. Climate Change Impacts on Extreme Events in the United States: An Uncertainty Analysis Monier and Gao May 2013

246. Probabilistic Projections of $21^{\text {st }}$ Century Climate Change over Northern Eurasia Monier et al. July 2013

247. What GHG Concentration Targets are Reachable in this Century? Paltsev et al. July 2013

248. The Energy and Economic Impacts of Expanding International Emissions Trading Qi et al. August 2013

249. Limited Sectoral Trading between the EU ETS and China Gavard et al. August 2013

250. The Association of Large-Scale Climate Variability and Teleconnections on Wind Resource over Europe and its Intermittency Kriesche and Schlosser September 2013

251. Regulatory Control of Vehicle and Power Plant Emissions: How Effective and at What Cost? Paltsev et al. October 2013

252. Synergy between Pollution and Carbon Emissions Control: Comparing China and the U.S. Nam et al. October 2013

253. An Analogue Approach to Identify Extreme Precipitation Events: Evaluation and Application to CMIP5 Climate Models in the United States Gao et al. November 2013

254. The Future of Global Water Stress: An Integrated Assessment Schlosser et al. January 2014

255. The Mercury Game: Evaluating a Negotiation Simulation that Teaches Students about Science-Policy Interactions Stokes and Selin January 2014

256. The Potential Wind Power Resource in Australia: A New Perspective Hallgren et al. February 2014

257. Equity and Emissions Trading in China Zhang et al. February 2014

258. Characterization of the Wind Power Resource in Europe and its Intermittency Cosseron et al. March 2014

259. A Self-Consistent Method to Assess Air Quality CoBenefits from US Climate Policies Saari et al. April 2014

260. Electricity Generation and Emissions Reduction Decisions under Policy Uncertainty: A General Equilibrium Analysis Morris et al. April 2014

261. An Integrated Assessment of China's Wind Energy Potential Zhang et al. April 2014

262. The China-in-Global Energy Model Qi et al. May 2014

263. Markets versus Regulation: The Efficiency and Distributional Impacts of U.S. Climate Policy Proposals Rausch and Karplus May 2014 